\section{OPEN ACCESS}

Edited by:

Jean Challacombe,

Twist Bioscience, United States

Reviewed by:

John Shearer Lambert,

University College Dublin, Ireland

Ryan Oliver Marino Rego,

Academy of Sciences of the Czech

Republic (ASCR), Czechia

*Correspondence:

Jason R. Bobe

jason.bobe@mssm.edu

tORCID:

Jason R. Bobe

orcid.org/0000-0003-1864-8609

Robert L. Moritz

orcid.org/0000-0002-3216-9447

Panga Jaipal Reddy

orcid.org/0000-0002-4481-3631

Specialty section:

This article was submitted to

Infectious Diseases - Surveillance,

Prevention and Treatment,

a section of the journal

Frontiers in Medicine

Received: 10 February 2021

Accepted: 12 July 2021

Published: 18 August 2021

Citation:

Bobe JR, Jutras BL, Horn EJ,

Embers ME, Bailey A, Moritz RL,

Zhang Y, Soloski MJ, Ostfeld RS,

Marconi RT, Aucott J, Ma'ayan A,

Keesing F, Lewis K, Ben Mamoun C,

Rebman AW, McClune ME,

Breitschwerdt EB, Reddy PJ,

Maggi $R$, Yang $F$, Nemser B, Ozcan A,

Garner O, Di Carlo D, Ballard Z,

Joung $H$-A, Garcia-Romeu A,

Griffiths RR, Baumgarth $N$ and

Fallon BA (2021) Recent Progress in

Lyme Disease and Remaining

Challenges. Front. Med. 8:666554.

doi: 10.3389/fmed.2021.666554

\title{
Recent Progress in Lyme Disease and Remaining Challenges
}

Jason R. Bobe ${ }^{1 * t}$, Brandon L. Jutras ${ }^{2}$, Elizabeth J. Horn ${ }^{3}$, Monica E. Embers ${ }^{4}$, Allison Bailey ${ }^{1}$, Robert L. Moritz ${ }^{5 t}$, Ying Zhang ${ }^{6}$, Mark J. Soloski ${ }^{7}$, Richard S. Ostfeld ${ }^{8}$, Richard T. Marconi ${ }^{9}$, John Aucott ${ }^{7}$, Avi Ma'ayan ${ }^{1}$, Felicia Keesing ${ }^{10}$, Kim Lewis ${ }^{11}$, Choukri Ben Mamoun ${ }^{12}$, Alison W. Rebman ${ }^{7}$, Mecaila E. McClune ${ }^{2}$, Edward B. Breitschwerdt ${ }^{13}$, Panga Jaipal Reddy ${ }^{5 \dagger}$, Ricardo Maggi ${ }^{13}$, Frank Yang ${ }^{14}$, Bennett Nemser ${ }^{15}$, Aydogan Ozcan ${ }^{16}$, Omai Garner ${ }^{16}$, Dino Di Carlo ${ }^{16}$, Zachary Ballard ${ }^{16}$, Hyou-Arm Joung ${ }^{16}$, Albert Garcia-Romeu ${ }^{17}$, Roland R. Griffiths ${ }^{17}$, Nicole Baumgarth ${ }^{18}$ and Brian A. Fallon ${ }^{19}$

${ }^{1}$ Icahn School of Medicine at Mount Sinai, New York, NY, United States, ${ }^{2}$ Department of Biochemistry, Fralin Life Sciences Institute, Virginia Tech, Blacksburg, VA, United States, ${ }^{3}$ Lyme Disease Biobank, Portland, OR, United States, ${ }^{4}$ Tulane University Health Sciences, New Orleans, LA, United States, ${ }^{5}$ Institute for Systems Biology, Seattle, WA, United States, ${ }^{6}$ State Key Laboratory for the Diagnosis and Treatment of Infectious Diseases, The First Affiliated Hospital, Zhejiang University School of Medicine, Hangzhou, China, ${ }^{7}$ Division of Rheumatology, Department of Medicine, Lyme Disease Research Center, Johns Hopkins University School of Medicine, Baltimore, MD, United States, ${ }^{8}$ Cary Institute of Ecosystem Studies, Millbrook, NY, United States, ${ }^{9}$ Department of Microbiology and Immunology, Virginia Commonwealth University Medical Center, Richmond, VA, United States, ${ }^{10}$ Bard College, Annandale, NY, United States, ${ }^{11}$ Department of Biology, Northeastern University, Boston, MA, United States, ${ }^{12}$ Yale University School of Medicine, New Haven, CT, United States, ${ }^{13}$ Department of Clinical Sciences, Comparative Medicine Institute, College of Veterinary Medicine, North Carolina State University, Raleigh, NC, United States, ${ }^{14}$ Department of Microbiology and Immunology, Indiana University School of Medicine, Indianapolis, IN, United States, ${ }^{15}$ Steven \& Alexandra Cohen Foundation, Stamford, CT, United States, ${ }^{16}$ University of California, Los Angeles, Los Angeles, CA, United States, ${ }^{17}$ Department of Psychiatry and Behavioral Sciences, Johns Hopkins University School of Medicine, Baltimore, MD, United States, ${ }^{18}$ Center for Immunology and Infectious Diseases and the Department of Pathology, Microbiology \& Immunology, School of Veterinary Medicine, University of California, Davis, Davis, CA, United States, ${ }^{19}$ Columbia University Irving Medical Center, New York, NY, United States

Lyme disease (also known as Lyme borreliosis) is the most common vector-borne disease in the United States with an estimated 476,000 cases per year. While historically, the long-term impact of Lyme disease on patients has been controversial, mounting evidence supports the idea that a substantial number of patients experience persistent symptoms following treatment. The research community has largely lacked the necessary funding to properly advance the scientific and clinical understanding of the disease, or to develop and evaluate innovative approaches for prevention, diagnosis, and treatment. Given the many outstanding questions raised into the diagnosis, clinical presentation and treatment of Lyme disease, and the underlying molecular mechanisms that trigger persistent disease, there is an urgent need for more support. This review article summarizes progress over the past 5 years in our understanding of Lyme and tick-borne diseases in the United States and highlights remaining challenges. 


\section{INTRODUCTION}

According to the Center for Disease Control and Prevention (CDC), the number of vector-borne diseases reported to the National Notifiable Diseases Surveillance System (NNDSS) between 2004 and 2016 reached a total of 642,602 cases. Of these, tick-borne diseases (TBDs) accounted for 77\% (491,671 cases) of reported cases with the total number of cases doubling in 13 years. The pace of emergence of new tick-borne disease cases increased not only for Lyme disease (LD), the most predominant TBD with $82 \%$ of cases, but also for spotted fever rickettsiosis, babesiosis, anaplasmosis, and Powassan disease (1). In this review, we highlight the major scientific advances made primarily in the field of LD research in the United States (USA).

LD, also known as Lyme borreliosis, is a growing health problem in the USA. LD is caused by pathogenic species in the Borreliella genus (for the relationship with the Borrelia genus, see section Genomic Insights From Borreliaceae Lineages). These spirochetal bacteria are transmitted from vertebrate reservoirs to human hosts through bites from infected Ixodes spp. ticks. Borreliella burgdorferi ( $B$. burgdorferi, hereafter $B b$ ) is the most common agent of LD in the USA (1). The CDC recently estimated $\sim 476,000$ clinician diagnosed cases of LD every year in the USA based on insurance claims data from 2010 to 2018 (2), a significant increase from their previous estimate of $\sim 329,000$ annual cases using similar methods to generate data from 2005 to 2010 (3). If untreated, infection with $B b$ can lead to health problems affecting the skin, joints, nervous system, or less commonly, the heart (4). While most individuals return to health following antibiotic treatment for $\mathrm{LD}$, others go on to experience chronic health problems that can last months to years. One well-defined clinical subgroup of LD patients who experience ongoing symptoms following treatment is Post-treatment Lyme disease (PTLD) (see section 2.3.2 PTLD). Medical costs related to $\mathrm{LD}$ and PTLD are estimated to be between $\$ 712 \mathrm{M}-1.3 \mathrm{~B}$ each year in the USA (5). The causes of PTLD are not yet well-understood but are an active area of research due to their critical importance to advancing therapy development and effective treatment for this patient population. The two most salient hypotheses for etiology of PTLD include persistence of infection or antigenic debris, persistence of inappropriate immune activation and inflammation, or some combination of these (see section Pathogenesis below). The research community has largely lacked the necessary funding to properly advance scientific and clinical understanding of $\mathrm{LD}$ and its sequelae, and to develop and evaluate new approaches for prevention, diagnosis, and treatment. The annual NIH investment in LD research so far has been small compared to many other infectious diseases (see Table 1) (6).

Considering the rapid growth in prevalence of LD and the risk for significant long-term health consequences of those infected (7), a multifaceted effort is needed to create better prevention practices, diagnostics, and treatments, along with advancing basic science about ticks, tick-borne pathogens, and the pathophysiology of LD. In this review, we summarize key advances in each of these areas over the past 5 years and identify challenges and opportunities for the field. We aim to highlight
TABLE 1 | NIH support for LD research is currently low compared to other infectious diseases.

\begin{tabular}{|c|c|c|c|}
\hline Disease & $\begin{array}{l}\text { NIH Funding } \\
\text { FY } 2018 \text { (in } \\
\text { millions) }\end{array}$ & $\begin{array}{l}\text { USA reported } \\
\text { cases in } 2018\end{array}$ & $\begin{array}{l}\text { Funding per } \\
\text { reported case } \\
\text { in } 2018\end{array}$ \\
\hline HIV/AIDS & $\$ 2,995$ & $36,400^{b}$ & $\$ 82,280$ \\
\hline Malaria & $\$ 202$ & $\sim 2,000^{\mathrm{C}}$ & $\sim \$ 101,000$ \\
\hline West Nile Virus & $\$ 36$ & $2,647^{d}$ & $\$ 13,600$ \\
\hline Lyme Disease & $\$ 30$ & 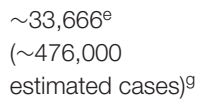 & $\begin{array}{l}\sim \$ 891 \text { (\$63 per } \\
\text { estimated case) }\end{array}$ \\
\hline Tuberculosis & $\$ 403$ & $9,029^{f}$ & $\$ 44,634$ \\
\hline
\end{tabular}

For purposes of consistency and comparison across diseases, the table uses funding per case based on the number of reported cases. A difference sometimes exists between the reported number of cases per year and estimates of the actual incidence in some infectious diseases. For $L D$, the difference is more than 10-fold. For example, the number of reported cases in the USA in 2018 is $\sim 34 \mathrm{k}$ while the estimated number of annual cases is $\sim 476 \mathrm{k}(\mathrm{g})$. Therefore, the research investment by the $\mathrm{NIH}$ for LD is around $\$ 63$ per new estimated case in 2018. This table is adapted and updated from a version in the Tick-borne Diseases Working Group (TBDWG) report to Congress (6).

a https://report.nih.gov/categorical_spending.aspx

${ }^{b}$ https://www.hiv.gov/hiv-basics/overview/data-and-trends/statistics

${ }^{c}$ https://www.cdc.gov/parasites/malaria/index.htm/

${ }^{d}$ https://www.cdc.gov/westnile/statsmaps/cumMapsData.htm/

e https://wonder.cdc.gov/nndss/static/2018/annual/2018-table2i.html

${ }^{f}$ https://www.cdc.gov/mmwr/volumes/68/wr/mm6811a2.htm

ghttps://www.cdc.gov/lyme/stats/humancases.html

many important studies, but due to space constraints, we are not able to discuss all relevant publications. Where available, we also reference more in-depth review articles on specific topics. While LD is a global public health concern across the Northern Hemisphere, this review article is largely USA-centric in terms of manuscripts discussed since aspects of LD vary geographically, including the primary causative agents and their vectors; pathogenicity and common disease manifestations; and the prevalence and incidence of disease.

\section{CLINICAL AND TRANSLATIONAL MEDICINE}

Next, we review progress in the diagnosis and treatment of LD, including emerging diagnostic assays and novel therapies. We also describe 2-well-defined subgroups of patients with posttreatment sequelae, including those with antibiotic-refractory Lyme arthritis (LA) and PTLD.

\section{Diagnosis}

The diagnosis of LD can be a complex task for the provider because, outside of the erythema migrans (EM) lesion of early LD, diagnosis relies on non-specific clinical signs and symptoms that may or may not be supported by laboratory evidence. A prospective study evaluated the ability of emergency room (ER) physicians across 5 hospitals in endemic areas in the Northeast of the USA to accurately discriminate between LD (early disseminated or late) and non-LD using clinical judgment alone, prior to the receipt of laboratory evidence. Among 
1,021 children being evaluated for LD (based on presence of one or more EM lesions or Lyme serology tests ordered and compatible symptoms) and enrolled in the study between 2015 and 2017, clinician suspicion of LD in the ER setting was found to be minimally accurate compared to diagnoses supported by laboratory evidence. Twelve percent of patients whom the treating clinician deemed to be unlikely to have LD, actually had LD. Thirty-one percent of patients whom the clinician deemed very likely to have $\mathrm{LD}$, actually did not have LD (8). A true case of early disseminated or late LD was defined in this study as those with compatible symptoms and positive two-tier serology per guidelines, the limitations of which are reviewed below. The accuracy of clinician assessment of patients presenting with a single EM lesion $(n=42)$ was not assessed. The challenges of discriminating between an EM lesion of LD and a non-EM lesion are included below, along with a description of a novel imaging tool that may aid clinician assessment of this sign of LD (9).

Many patients struggle with getting a timely diagnosis and treatment for LD. Around $40 \%$ of patients diagnosed with LD have signs and symptoms associated with disseminated or late $\mathrm{LD}$, indicating that delayed diagnosis and treatment are a common occurrence (10). In a recent population-based study of 778 patients surveyed in Pennsylvania who were treated for LD in the past 5 years, $31 \%$ had a time to treatment $>30$ days and $10 \%$ had time to treatment $>6$ months, where time to treatment is defined as the sum of time to first medical contact and time under care until receiving treatment (11). A qualitative study of 26 patients treated for LD in Pennsylvania suggests that patient appraisal of their own signs and symptoms plays a role in delayed treatment, specifically the misattribution of nonspecific symptoms, the intermittent nature of symptoms and the lack of a "bull's-eye rash," which is commonly misunderstood to be the only representative skin lesion of LD (12). High rates of initial delayed or misdiagnosis is also commonly reported by LD patients that meet the PTLDS case definition (13) or those with chronic symptoms more broadly (14).

The consequences of the diagnostic challenges in $\mathrm{LD}$ are potentially significant for patients and may lead to missed or delayed diagnosis and exposure to inappropriate or inadequate treatment. Next, we review some recent findings and the current challenges related to the diagnosis of LD.

\section{Exposure to Ticks}

The collection of tick exposure history from patients suspected of having LD lacks sensitivity because ticks are stealth biters. They are able to avoid detection by human hosts during feeding. Many people diagnosed with LD have no recollection of being bitten by a tick (15). While the major endemic regions in the USA are the Northeast (16), mid-Atlantic and upper Midwest states, Ixodes spp. ticks capable of carrying LD pathogens are found in many states. A recent citizen-science based effort to collect ticks submitted by volunteers from across the USA identified ticks capable of carrying Borreliella species in 35 states (17). In California, where LD is not considered endemic, infected Ixodes spp. ticks have been found in 42 counties (72\%) according to surveillance data (18).

\section{Serological Testing}

Two-tiered serological testing is widely used to support the diagnosis of LD. The two-tiered testing algorithm consists of a first-tier enzyme immunoassay (EIA) or ELISA, and for samples that are positive or equivocal (borderline) on the first tier, a second tier immunoblot is performed. Using the CDC's algorithm, the immunoblot is positive if at least 2 of 3 bands are present on the IgM immunoblot within 30 days of symptom onset or 5-10 bands are present on the IgG immunoblot at any time (19). A modified two-tiered testing algorithm was approved by the CDC in 2019, which uses a first-tier ELISA, and instead of the confirmatory immunoblot, uses 1 or 2 additional ELISAs that target different antigens than the first-tier ELISA (20).

Serology presents several challenges for accurate diagnosis. The human body takes time to generate anti- $B b$ antibodies, so serological testing is not sensitive during early infection (2124) - the period when treatment is most likely to succeed. For patients with disseminated LD or later manifestations such as late Lyme arthritis, serological testing has improved performance compared to early disease $(22,25,26)$. However, current tests also lack sensitivity following antibiotic treatment of acute LD, as seroconversion occurs less frequently (21, 23, 27-30). Rebman et al. ran two-tier serology on acute and convalescent sera samples collected from 104 patients with clinician-diagnosed EM rash and 21 days of antibiotic treatment. They observed $41(39.4 \%)$ of these patients were seronegative at both the acute and convalescent time points; only 7 (6.7\%) patients were observed to have IgG seroconversion at either time point (29). Seroconversion was also rare in samples from the Lyme Disease Biobank, where only 3 of 83 samples (3.6\%) from patients with $\mathrm{EM}>5 \mathrm{~cm}$ seroconverted at the convalescent draw (2-3 months after the acute draw) (23). Other widely known limitations of serological tests are that they are unable to distinguish between a prior exposure to $B b$ and an active infection, may crossreact with non- $B b$ antibodies, are subject to variable results depending the selection of antigens used in the first-tier test (31) and some assays, especially the Western immunoblot, require interpretation that may introduce bias $(32,33)$.

For patients with an EM $>5 \mathrm{~cm}$ in an endemic area with a history of tick exposure, a clinical diagnosis is sufficient (34). Testing is not indicated in these patients, and the serologic tests would likely be negative due to lack of antibody development in early disease. For patients with early LD presenting without EM, diagnosis is incredibly challenging.

\section{Signs and Symptoms}

If untreated, a patient with a $B b$ infection may go through several stages of $\mathrm{LD}$, with different signs and symptoms at each stage [reviewed in (35)]. In most people, the first stage of LD begins with "flu-like" symptoms and an EM lesion. LD is known as the "great imitator" because symptoms are varied and often overlap with common health complaints, sometimes making early diagnosis more difficult $(36,37)$. The most common symptoms of early LD are fever, chills, headache, fatigue, neck stiffness, myalgia, joint pain and swollen lymph nodes. There are likely hundreds of health conditions with significant overlap with these non-specific signs and symptoms. As spirochetes 
disseminate from the site of the tick bite, additional EMs and manifestations can occur including 7 th cranial nerve palsy, meningitis, or Lyme carditis [reviewed in (38)]. In the third stage, without proper treatment, patients may also experience neuroborreliosis or Lyme arthritis (LA).

The type and severity of LD manifestations are known to vary across infected individuals for reasons that are unclear but are likely attributable to both, differences in the infecting pathogen and the characteristics of the infected individual. They range from asymptomatic or subclinical infection (39-41) all the way to severe complications from LD that, in rare cases, result in death from Lyme carditis $(42,43)$.

\section{EM Lesion}

The characteristic EM lesion develops inconsistently across humans 3-30 days following a bite from an infected tick (44). The EM is often an annular, erythematous, expanding cutaneous lesion that may or may not have a central clearing. While it is sometimes referred to as a "bulls-eye rash," presentation is known to vary considerably $(15,45-47)$. Variation in skin pigmentation, as well as coloring and shape of the rash may also lead to missed or delayed clinical diagnoses (48). The central clearing in the rash is reported to be less common in endemic areas compared to nonendemic areas (15). While reports vary across studies, up to $30 \%$ of individuals diagnosed with LD do not develop an EM lesion $(47,49-52)$ or its presence is missed. If an EM lesion is absent, there is no clinically recommended laboratory test available to aid in the diagnosis of early LD because the currently recommended serologic tests are highly insensitive in the first few weeks of infection (51).

\section{Direct Detection of $\mathrm{Bb}$}

Many bacterial infections are diagnosed using a variety of culture methods and the confirmation of pathogen identity through molecular techniques or differential biochemical assays $(53,54)$. This is not currently practical or feasible for LD. The direct detection of the pathogen in blood can be a challenge because of the narrow window of spirochetemia that is more likely during early infection and the low numbers of circulating $B b$ $(55,56)$. While the pathogen may disseminate from the site of the tick bite through the blood, it also disseminates through the lymphatics and is known to invade other more privileged tissues, such as the heart, nervous system, and connective tissue. $B b$ is a fastidious, slow-growing bacteria that requires up to 12 weeks of incubation in culture before a negative result is determined, which is too long to be useful in clinical diagnosis (32). In one study on the ability to detect spirochetemia in patients with EM through culture methods, they estimated 1 cultivable spirochete per $10 \mathrm{~mL}$ of whole blood (55). $B b$ culture also requires specialized skills and tools that most laboratories are not equipped with outside of the research setting, where these techniques remain valuable for basic science research (21). Finally, antibiotic treatment decreases culture positivity rates, making it useful only in untreated patients (21). Blood, serum or plasma is not a reliable tissue to detect $B b$ by PCR because the spirochetes are transient and in low copy number. Skin biopsy from the EM lesion is a more useful tissue diagnostically, but this step is invasive and patients that present with an EM lesion do not require laboratory confirmation for diagnosis of LD (21).

\section{Emerging Diagnostics}

For the reasons outlined above, there is an urgent need for pathogen-detection methods that are highly sensitive and specific and capable of reliably detecting infection by multiple pathogenic species of Borreliella and strains of $B b$ (see section Genomic Insights From Borreliaceae Lineages) at all stages of infection and disease (57). Of special concern are individuals with acute infection that do not present with an EM rash and have yet to generate a humoral response to $B b$. The factors that control the development of EM rash also need to be delineated, along with a surrogate set of biomarkers to aid diagnosis of more complex cases of suspected LD. Ixodes ticks can carry multiple human pathogens (see section Transmission of $B b$ via Ixodes spp. Vectors), and diagnostic methods capable of detecting the most prevalent tick-borne pathogens and clinically relevant strains of Borreliella are needed. Promising new diagnostic methods are being developed using serology, direct detection assays, and other tests that measure host response to the pathogen. Select assays are outlined in Table 2. There is also a significant unmet need for diagnosing PTLD. Currently, this diagnosis is performed, in part, based on self-reporting of symptoms. Several groups are investigating correlation between blood transcriptome; blood metabolome; and gut microbiome of PTLD patients in search of potential diagnostic and causal markers. Of note are recent studies describing a distinct microbiome signature (58) and a blood metabolome signature (59).

\section{Treatment}

\section{Recommended Treatment}

Antimicrobial therapy for LD is often successful, especially when patients are treated in the early phase following detection of an EM lesion (79). As disease progresses, treatment must be extended and may be less effective $(80,81)$. Administration of doxycycline or amoxicillin for 14-21 days is the recommended treatment for early or early disseminated phase patients who do not have neurological involvement (44). Lyme arthritis is an indication of disseminated disease and the recommended treatment for this is the aforementioned oral antibiotic for 28 days. For patients with clinically evident neurological involvement, treatment with intravenous ceftriaxone is recommended. These suggested regimens are based on objective measurements. However, in the guidelines from the Infectious Disease Society of America (IDSA), the authors point out that "Response to treatment is usually slow and may be incomplete" (82).

There is widespread agreement in the medical community about the appropriate treatment of acute LD (83), however the appropriate treatment of patients meeting the Post-treatment Lyme disease syndrome (PTLDS) case definition remains a challenge due to incomplete knowledge about the condition and related uncertainties. Moreover, the recently updated IDSA guidelines for the treatment of LD remove mention of PTLDS altogether (83). 
TABLE 2 | Emerging diagnostic assays for LD.

\begin{tabular}{|c|c|c|}
\hline Test & Description & References \\
\hline \multicolumn{3}{|l|}{ Serological assays } \\
\hline TBD-Serochip & Array assay that discriminates antibody response to 8 tick-borne pathogens & $(60)$ \\
\hline mChip-Ld & Multiplex microfluidics assay targeting $3 \mathrm{Bb}$ antigens for POC use & $(61)$ \\
\hline $\mathrm{xVFA}$ & Multiplex paper based lateral flow assay targeting $7 \mathrm{Bb}$ antigens for POC use & $(62)$ \\
\hline \multicolumn{3}{|c|}{ Direct detection assays } \\
\hline Karius test & Microbial cell-free DNA unbiased metagenomic sequencing & $(63,64)$ \\
\hline PCR-ESI/MS & Direct detection PCR with electrospray ionization mass spectrometry & $(24,65)$ \\
\hline Nanotrap urine & Nanotrap assay to measure $B b$ OspA c-terminus peptide & $(66)$ \\
\hline \multicolumn{3}{|c|}{ Host-focused assays } \\
\hline Transcriptome & Transcriptome profiling by RNA-Seq to identify gene expression signature & $(67,68)$ \\
\hline Proteome & Targeted mass spectrometry-based approach to identify protein biomarkers & (69) \\
\hline SERA & Antibody repertoire analysis to identify Lyme specific motifs & $(70)$ \\
\hline ImmunoSEQ & T-cell receptor sequencing to identify Lyme specific signature & $(71)^{2}$ \\
\hline Microbiome & Microbiome sequencing to identify Lyme specific signature & $(58)$ \\
\hline Metabolomics & LC-MS/LC-MS-SRM to analyze small molecule metabolites to develop biosignature & $(59,72-75)$ \\
\hline QuantiFERON-Lyme & Assay that measures IFN- $\gamma$ release from T-cells in response to $B b$ & $(76)$ \\
\hline \multicolumn{3}{|l|}{ Imaging } \\
\hline Image Analysis & Deep learning algorithms that discriminate between EM and other skin lesions & $(9,77)$ \\
\hline HS-198 & A small-molecule fluorescent conjugate that targets a conserved protein in $\mathrm{Bb}$ for in vivo imaging. & $(78)$ \\
\hline
\end{tabular}

Bb, B. burgdorferi; POC, Point of care; LC-MS, Liquid chromatography-mass spectrometry.

More clinical trials are needed to assess the efficacy and safety of drug regimens and complementary therapies for LD and its sequelae. This year, the first clinical trial coordinating center was established at Columbia University to facilitate the conduct of high-quality multi-site clinical trials and pilot studies related to LD and other TBDs. ${ }^{1}$ Furthermore, tools capable of discriminating the etiology of persistent health issues following treatment for $\mathrm{LD}$ are needed in order to improve therapy development efforts and target treatments for more precise patient-centered care.

\section{Drug Discovery and Preclinical Studies}

Although early-stage LD can be successfully treated with doxycycline or amoxicillin, late-stage LD with arthritis and neurological symptoms can be refractory to antibiotic treatment. $\mathrm{Wu}$ et al. showed that stationary phase $B b$ are unexpectedly susceptible to cell wall synthesis inhibitors, and vancomycin in particular almost completely eradicates persisters in vitro (84) (see section Persistent Infection). Feng et al. recently identified FDA-approved drug candidates that are more effective at killing dormant $B b$ persisters in vitro than the current Lyme antibiotics (85). They found the drug combination Daptomycin + Cefoperazone (or Cefuroxime) + Doxycycline was most effective at eradicating $B b$ grown in vitro and more recently in the mouse model for $B b$ persistence $(86,87)$.

\section{Complementary Therapies}

Zhang et al. recently identified natural products and botanical medicines (Cryptolepis sanguinolenta (Yellow dye root),

$\overline{{ }^{1} \mathrm{https} / / / \text { www.columbia-lyme.org/clinical-trials-network }}$
Juglans nigra (Black walnut), Polygonum cuspidatum (Japanese knotweed), Uncaria tomentosa (Cat's claw), Artemisia annua (Sweet wormwood), Cistus incanus, and Scutellaria baicalensis (Chinese skullcap) with good activity against both stationary phase and growing $B b(88)$. More recently, botanical medicines Cryptolepis sanguinolenta, Artemisia annua, Scutellaria baicalensis, Polygonum cuspidatum, and Alchornea cordifolia have also been shown to have activity against Babesia duncani (89). Since the above herbal medicines that have activity against $B b$ and Babesia have been used traditionally in patients with good safety profile, proper clinical trials are needed to evaluate their utility in treating patients with LD and coinfections. In addition, some essential oils such as oregano, cinnamon bark, clove bud, citronella, garlic, allspice, myrrh, hydacheim, and Litsea cubeba were shown to have excellent activity against both stationary phase and growing $B b(88,90)$. However, further studies are needed to evaluate the active compounds in the essential oils, in order to elucidate the specific activity, to assess their potential toxicity and pharmacokinetic properties for activity against $B b$ infection in animal models before human use.

\section{Well-Defined LD Patient Subgroups With Posttreatment Sequelae}

Antimicrobial therapy effectively treats LD in most people, however some patients experience ongoing health issues following treatment $(4,91)$. Antibiotic-refractory LA is the most well-characterized subgroup of patients with posttreatment sequelae. In recent years, characterization of patients with PTLD, a well-defined subset of patients with persistent or chronic LD, has also advanced considerably. Next, we review progress in the description of each of these post-treatment sequelae. 


\section{Antibiotic Refractory LA}

The LD patient subgroup with LA has been meticulously studied for decades. In 1975, a cluster of cases was brought to the attention of the Connecticut State Department of Health independently by two mothers concerned about the number of children with swollen knees with similarities to juvenile arthritis, a rare condition. An investigation revealed 51 similar cases (39 of these children) in Old Lyme, Connecticut and adjacent townships (92). By 1983, the causative agent and vector of LD were identified (93). LA-the proliferative and persistent synovitis of one or more large joints-is the most prevalent symptom in late-stage LD patients [reviewed in (94)]. LA may wax and wane months to years following untreated infection (95). Around $10 \%$ of LA patients experience persistent LA that does not resolve within a couple months after one or more rounds of antibiotic therapy (95-97). LA patients refractory to oral antibiotics are treated with intravenous ceftriaxone antibiotic therapy, with mixed results in adults $(97,98)$ and children $(99)$. Persistent LA despite aggressive treatment with antibiotics is referred to as antibiotic refractory LA (100), or if no evidence of ongoing infection, post-infectious LA (101). Among patients with persistent Lyme arthritis, determining whether persistent joint inflammation is due to an ongoing antibiotic-refractory infection or a post-infectious immune response also raises important treatment dilemmas that are not yet resolved, as reviewed elsewhere (95). The true cause of antibiotic-refractory LA has remained enigmatic. Recent developments, however, suggest a complex interplay between both bacterial and host factors (102).

What bacterial components may contribute to inflammation after therapy? While the debate surrounding persistent infection continues (see section Persistence), undetectable levels of bacteria in the SF of some patients with antibiotic refractory LA has led to a search for alternative explanations for persistent inflammation. Intravital microscopy studies of antibiotic treated mice observed the persistence of $B b$-derived material (103), which precipitated the possibility that bacterial debris may be responsible for immune activation. Later, we highlight a recent finding that a component of the bacterial cell envelope may exacerbate and prolong the initial response to the LD agent (see section Persistent Antigenic Debris).

\section{PTLD}

PTLD is a narrow but defined subset of patients with persistent symptoms following treatment for LD [reviewed in $(30,44)$ ]. Patients with PTLD suffer persistent or relapsing symptoms, such as severe fatigue, cognitive issues, sleep disturbance, and musculoskeletal pain that negatively impact their functional abilities at least 6 months following treatment for LD. The reductions in quality of life for patients with PTLD are comparable to patients suffering from congestive heart failure (104, 105). These health problems can last months or years following the initial treatment for LD. The incidence of PTLD is as high as $20 \%$ in some patient populations $(13,44,91,106-$ 108). Prevalence of PTLD is currently difficult to ascertain, due in part to the variability in the case definition applied in the literature and variability in reported rates of treatment failures among patients with $\mathrm{LD}$, so estimates range from 69,000 to more than 1 million cases in the USA $(107,109)$.

Descriptions of patients with persistent symptoms following antibiotic treatment for $\mathrm{LD}$ date back to studies in the 1980's (110, 111) and 1990's (79, 80, 112, 113). The term "post-treatment [chronic] Lyme disease syndrome" and a case definition PTLDS were first described in 2003 (114) and 2006 (44), respectively. Today this case definition, along with standardized measurement of subjective symptoms (115), informs the eligibility and exclusion criteria for many studies and trials related to the broader and more heterogeneous population with chronic or persistent Lyme $(91,116,117)$, so that outcomes from research studies may be compared and potential mechanisms of pathogenesis defined with less ambiguity (44). Recent studies have deployed deep phenotyping methods and identified multiple biomarkers that distinguish these patients from LD patients that return to health and/or controls, as described below. These studies provide evidence that PTLD is an infection-associated condition with a distinct biology. Here and throughout, we adopt the terminology PTLD, as previously proposed $(44,118)$, to describe this condition.

The diagnosis and treatment of patients with PTLD face significant challenges. Objective tests to diagnose PTLD currently do not exist. Instead, diagnosis is made clinically through a process of documenting a prior history of LD and excluding other potential causes of persistent symptoms. Currently there are no prognostic indicators to stratify LD patients for their susceptibility to PTLD, but elevated levels of the T-cell chemokine CCL19, IL-23 or muted B-cell response were recently reported to be more common among PTLD patients compared to those that return to health following initial treatment (119-121). For patients that progress to PTLD, there are no FDA approved curative therapies. Safety and efficacy data for off-label treatment regimens and complementary therapies for PTLD are not wellestablished. Objective tests to determine whether a patient is cured or responsive to therapy also do not exist.

Objective laboratory tests that improve the diagnosis and treatment of this patient subgroup appear to be on the horizon in part due to investments in the creation of carefully constructed cohorts and biorepositories of well-defined patients with PTLD (see section Biorepositories and Research Cohorts). For example, the first biomarker of PTLD to be identified in one cohort that was then confirmed in a second, independent cohort of PTLD patients in the USA was published in 2020. This metabolomic signature discriminates clinically cured LD patients without PTLD from LD patients with PTLD (59). Alteration of gene expression was shown to persist after treatment for early LD among a small sample of patients followed longitudinally for 6 months. While no transcriptome signature was identified that could discriminate between patients that return to health after treatment compared to those that do not, the signature may lead to new objective tests for early LD (67). A gut microbiome signature was also recently identified that could distinguish PTLD patients from both healthy controls and ICU patients, further suggesting that PTLD is a distinct and definable disorder even if the underlying etiology remains uncertain (58). Other biomarkers related to LD and PTLD are reviewed 
below (section Pathogenesis). Taken together, these findings indicate that novel diagnostics and treatments for PTLD are now within reach.

\section{FUNDAMENTAL KNOWLEDGE Genomic Insights From Borreliaceae Lineages}

Between 1982 and 2010, the B. burgdorferi species complex, known as B. burgdorferi sensu lato, steadily expanded from 1 to 18 species (sometimes referred to as genospecies) as isolates from tick vectors, their hosts, and patient samples were characterized [reviewed in (122)]. A subset of these species are associated with human disease. B. burgdorferi sensu stricto $(B b)$ in the USA, as well as B. afzelii and B. garinii in Eurasia are the most common agents of LD in the Northern hemisphere. Cases of LD in Europe are also caused by $B b$ and B. bavariensis (123), but are less common. B. spielmanii (124), B. bisettiae (125-127), and B. lusitaniae $(128,129)$ have been identified in human specimens but their clinical importance is less clear. B. valaisiana has been identified in human specimens (130), but others have recently provided compelling reasons why existing evidence does not support it being considered a human pathogen (131). Additional species have been identified in tick vectors or their hosts, but not in patient samples.

The genus Borrelia was recently divided into two genera (132, 133). This division groups the tick- and louse-borne relapsing fever (RF) agents and their relatives into the genus Borrelia and the $\mathrm{LD}$ agents and their relatives into the genus Borreliella. Historically, Borrelia species were classified according to whether they were transmitted by hard-bodied or soft-bodied ticks (134). The advent of molecular characterization through genetic analyses, and more recently, whole genome sequencing, has led to a refinement in our ability to classify spirochetes that are morphologically very similar. The division of the genus is based on phylogenetic and comparative genomic analyses using 38 public genomes of 18 different species. Due to naming standards, RF agents retain the genus Borrelia since they were the first species identified in the genus. The reclassification of Borrelia burgdorferi sensu lato species to the genus Borreliella means that their names will change but the abbreviations are retained, e.g., B. burgdorferi for Borreliella burgdorferi (Bb). The proposal generated considerable debate across the scientific community $(135,136)$. While adoption of the new naming convention has thus far been low in recently published literature, canonical bacterial reference manuals (133) and scientific databases have begun to incorporate the change.

New clinically relevant Borreliella species continue to be discovered [reviewed in $(134,137)$, reviewed in (138), reviewed in $(139,140)]$. In 2016, a new pathogenic species, B. mayonii, was identified in the upper Midwest of the USA through PCR analysis of more than 100,000 human tissue specimens collected between 2003 and 2014. Specimens from a total of six patients were deemed positive for B. mayonii, all presenting after 2012 with signs and symptoms consistent with LD (141). The genomes of two B. mayonii isolates have been sequenced, with notable differences from $B b$ (strain B31) including the absence of the complement inhibitor Cszp and dozens of other proteins (142).

$B b$ has one of the most complex genomes of any bacteria characterized to-date [reviewed in (143)]. Bb contains a single linear chromosome of $\sim 900 \mathrm{k}$ base pairs (bp) with between 7 and 21 different plasmids, ranging in size from 5 to $84 \mathrm{kbp}$ as reviewed from the genome sequences for $27 \mathrm{Bb}$ isolates determined since the elucidation of the $B b$ B31 genome sequence in 1997 (144). The single chromosome appears to be very constant in gene content and organization across these $B b$ isolates. Overall, dozens of Borreliella isolates have been sequenced (144-147). These include the partial genomes of 64 isolates recently identified from collections across Canada, an emerging area for LD (148). Todate, chromosome assemblies have been reported from these isolates without, however, an equivalent analysis of the plasmid content. In the $B b$ genome, the conserved linear chromosome encodes most housekeeping genes, while the variable set of linear and circular plasmids encodes most of the outer membrane lipoproteins (149-151). Three plasmids, cp26, lp17, and lp54, are conserved across sequenced isolates of $B b$ to-date [reviewed in (143)]. The content and number of the plasmids however appear much more variable with some loss of these once $B b$ is in vitro cultured for an extended period of time. It is noteworthy that while extra-chromosomal DNAs are often referred to as plasmids-non-essential DNA that carries pathogenic and/or material that infer a selective advantage in a particular situationsome $B b$ "plasmids" carry essential genes and are more akin to mini-chromosomes. Knowledge about plasmids is currently limited due in part to the constraints next-generation sequencing technologies impose with short reads and the subsequent challenges with assembly. Long-read sequencing technology is poised to enhance our understanding of plasmid content and their dynamics across species and strains $(150,152)$.

Characterization of Borreliella isolates at the genome level is important to determine how genomic variation correlates with different disease phenotypes [reviewed in $(122,157)]$. Molecular typing is used to classify distinct lineages of Borreliella. Common methods include pan-genome snp analysis (153), multi-locus sequence typing (MLST) (154), ribosomal RNA intergenic spacer typing (RST), and outer surface protein C (OspC) typing [(150), reviewed in (155)]. These methods for the classification of strains of $B b$ yield different numbers of distinct groups. Isolates of $B b$ from clinical samples collected from patients in the USA and Slovenia were recently compared and distinct differences were observed across genotypes, clinical manifestations, and inflammatory potential (156). In another recent study, serial blood samples obtained over a 21 day period from four patients with acute $\mathrm{LD}$ were assessed for infection with $B b$ via a novel direct detection method that combines PCR and electrospray ionization that is also able to discriminate different $B b$ genotypes. Two of 4 patients were infected with more than one genotype of $B b$. Notably, the dominant $B b$ genotype changed over time in these two patients during antibiotic treatment (65). Infection with heterologous strains of $B b$ in humans is consistent with studies of pathogen burden in both ticks and vertebrate hosts (see section Transmission of $B b$ via Ixodes spp. Vectors). New technologies and high-throughput screening methods are 
advancing our understanding of which genes in the $B b$ genome are critical for ecologically or clinically relevant phenotypes, such as infectivity, tissue tropism (157) or drug tolerance. In a series of recent experiments, transposon insertion sequencing (Tn-seq) was used to identify genes associated with mammalian infection, resistance to oxidative stress, and survival in tick vectors (158160).

LD agents are believed to inflict damage to people through inflammation caused by their immune response. No exotoxins have been identified in the genome with similarity to any previously described exotoxin found in other bacterial species, and the necessary secretory components appear to be absent. In addition, unlike most classical diderms, $B b$ does not produce the endotoxin Lipopolysaccharides (LPS) (144). A genome-wide proteome screen for immunogens in $B b$ (B31) using sera from patients with natural infections found that about $15 \%$ of the 1,292 open reading frames evaluated code for products that are immunogenic (161). More than 120 lipoproteins are encoded in the $B b$ genome (162) and represent nearly $8 \%$ of open reading frames (163). Of 125 lipoproteins examined experimentally, 86 of these are secreted to the bacterial surface (162).

\section{Proteomic Insights From Borreliaceae Lineages}

The application of mass spectrometry-based proteomics has recently gained interest in the field of $B b$ and $L D$ research to advance the understanding of disease pathogenesis and develop potential diagnostic methods and vaccines. Progress in $B b$ proteomics has been limited primarily to the proteins contained in the chromosome, while proteins encoded in the extra-chromosomal plasmids remain poorly characterized. In either case, attention has also been focused substantially on proteins encoded by genomic sequences of $B b$ that are homologs of B31-the vastly used isolate that was first collected from Shelter Island, New York (164). Further, very few laboratories working on proteomic workflows generate high-quality genomic data from different isolates of $B b$. Nevertheless, advanced mass spectrometry-based proteomics provide unmatched information such as protein identification, quantification and post-translational modifications. The characterization of the $B b$ proteome enables basic science research and the development of vaccines and diagnostics (44, 165). Though several proteomic studies have been published, no highresolution mass spectrometry (MS) data is represented in a publicly accessible repository for the community to access and utilize in research goals $(162,166,167)$. The recent construction of the Borreliella PeptideAtlas repository (http:// www.peptideatlas.org/) provides a unique community resource that contains large-scale assembly of observed and MS-derived validated data uniformly processed through the Trans-Proteomic Pipeline (TPP) (168). This database contains the proteome information from $B b$ isolates B31, 5A4, 297 and MM1 where 39,145 distinct peptides are validated and represent 1,283 $\mathrm{Bb}$ proteins. In addition to the unique peptide identification data, post-translational modifications are also presented with their validated MS spectra. The Borreliella PeptideAtlas is a dynamic proteome resource in terms of size and complexity and is continually updated as new datasets of $B b$ proteomes become available. These new datasets are ingested, processed through the TPP data analysis pipeline to ensure low false-discovery rates and presented in the conglomerated relational database for all users to explore and utilize. For example, the data can be mined to provide leading candidates across the isolates represented and the experimental conditions they were subjected to allowing exploration of how $B b$ adapts to, and is able to survive in a wide variety of environmental conditions. This resource provides a foundation for researchers to understand the dynamics of proteome organization throughout stages of infectivity and to generate targets to arrest infectivity.

\section{Transmission of Bb via Ixodes Spp. Vectors}

The black-legged ticks, Ixodes scapularis and Ixodes pacificus on the West Coast, are the primary vectors of $B b$ in the USA. In endemic areas, the proportion of Ixodes spp. ticks infected with $B b$ can be remarkably high. One recent survey of the pathogen burden of 197 Ixodes scapularis ticks collected from New York and Connecticut where LD is endemic, revealed 111 (56\%) ticks were infected with $B b$ and 37 (19\%) were co-infected with more than one human pathogen (169). The high pathogen burden is consistent with previous tick surveys in the same region (170). In contrast, the percent of infected ticks in other regions of the USA is much lower. In recently published surveys across California, for example, fewer than $5 \%$ of Ixodes spp. ticks were infected $(17,170)$. Ixodes ticks sometimes carry multiple strains of $B b$ $(65,150,171-173)$ that may impact the course of disease in people that are co-infected. One tick survey showed that $39 \%$ of Ixodes ticks in North America are infected with multiple genotypes of $B b$ (170).

Ixodes scapularis ticks feed only once per life stage (larvae, nymph, adult) after hatching from eggs. They primarily acquire $B b$ through feeding on infected vertebrates that are mostly mammals, but also some species of birds (174). $B b$ spirochetes colonize and persist in the tick until some are transmitted to a new host during the next feeding, while others remain in the tick during molting and the next life stage (175). $B b$ spirochetes are not transmitted from the adult tick to the egg, or it may occur only rarely. While transovarial transmission (TOT) of $B b$ in Ixodes spp. ticks has been reported in the literature, these reports may be attributable to confusion between $B$. miyamoto $i$, a relapsing fever agent, and $B b(176,177)$.

$B b$ spirochetes have evolved multiple mechanisms to aid survival in adverse environments throughout the enzootic cycle. While colonizing the tick gut they must impede immune defenses of the tick, those of the host blood meal, and coexist with other residents of the tick gut microbiome. After their migration from the tick gut through the tick body cavity (hemocoel) and into the tick salivary glands, $B b$ spirochetes are expelled during feeding into the next host where they must again impede immune defenses and change their gene expression to survive and establish infection in a vertebrate host. The diverse and dynamic interactions between $B b$ and Ixodes ticks during $B b$ colonization, persistence, and transmission was recently reviewed elsewhere (178), but several recent findings are worth highlighting here. 
The stability, abundance and diversity of the tick gut microbiome in Ixodes spp. is unsettled (179, 180), but there is evidence that the microbiome impacts the ability of $B b$ to effectively colonize the tick gut (181). The $B b$ genome lacks interbacterial defense pathways, which suggests they may not thrive in polymicrobial environments and the presence of certain taxa may interfere with colonization and persistence in the tick gut. For example, Pseudomonas possess genes for a Type VI secretion system that can deliver toxins to bacterial and eukaryotic members also residing in the tick gut microbiome $(179,182)$. Consistent with these findings, ticks infected with Pseudomonas are associated with lower burden of $B b$ (179, 182). Future research on the tick microbiome may lead to insights about approaches to disrupt pathogen colonization and transmission.

The tick salivary glands are important for transmission of $\mathrm{Bb}$ spirochetes. Tick saliva is essential to adequate tick feeding and contributes to human infection [reviewed in (183), reviewed in (184), reviewed in (185)]. During feeding, a tick alternates between secreting saliva and ingesting blood meal. Tick saliva not only carries pathogens from the tick into the host, but also contains molecules that function to aid the feeding process by creating blood flow through vasodilation and anticoagulative properties (186), blocking pain and itch (187, 188), impeding wound healing (189), and suppressing host immune response $(190,191)$. The composition of proteins expressed in tick saliva changes during feeding, which suggests another potential mechanism for host immune evasion through antigenic variation (192). A greater understanding of the components of tick saliva that support the infectivity of $B b$ may provide new routes to the prevention of LD.

\section{Pathogenesis}

The pathogenesis of LD is believed to be driven in large part by the immune response of patients, although the underlying causes of ongoing inflammation and tissue damage in different stages of $\mathrm{LD}$ remain an active area of research. The microbial origin and inflammatory nature of untreated LD is better understood than the pathophysiology that underlies persistent signs and symptoms of disease experienced by some individuals following antimicrobial treatment. The dominant hypotheses about potential mechanisms underlying PTLD are immune inflammation and dysregulation and persistent infection and/or persistent antigenic debris. In this section, we review progress in the past 5 years on our understanding of pathophysiology of $\mathrm{LD}$, starting with untreated LD. Then, we will review new evidence that has emerged related to persistent disease following treatment.

\section{Immune Activation and Inflammation in Untreated LD}

Inflammation is an important mechanism the body uses to aid in the elimination of pathogens. However, too much inflammation, such as what happens during a "cytokine storm" among some severe COVID-19 patients when cytokines are overproduced, can overwhelm the body and cause grave tissue injury. An aberrant inflammatory response is also what underlies autoimmune disease (193). In this section we review immune activation and inflammation associated with LD that begins soon after an infection with $B b$ from a tick bite.

The skin is an important first barrier to $B b$ infection. Interactions between the pathogen and human skin begin at the site of the tick bite where $B b$ spirochetes invade then disseminate outwardly, sometimes causing circular or elliptical EM lesions in their wake. One study induced suction blisters over EM lesions of LD patients in order to characterize the dermal leukocytes and cytokines of the aspirates from the skin. They found the aspirates to be enriched for T cells, monocytes/macrophages, and dendritic cells (DCs) compared to uninfected controls. Two cytokines, IL-6 and INF- $\gamma$, were predominant in the EM lesions (194).

The response of the innate immune system, including complement pathways and acute-phase proteins (APPs), occurs more or less immediately while the adaptive $\mathrm{B}$ - and Tcell response may take days to weeks. Macrophages and dendritic cells resident in the skin express a range of pattern recognition receptors (PRRs) that initiate signaling cascades and inflammatory responses as an early line of defense when they encounter and internalize a $B b$ spirochete [reviewed in (195)]. A yeast display screen of $>1,000$ extracellular and secreted human proteins identified direct interactions between $B b$ isolates and one human host factor, Peptidoglycan Recognition Protein 1 (PGLYRP1). In vitro assays show recombinant PGLYRP1 binds with purified peptidoglycan from $B b$ and have borrelicidal activity (196). In murine models deficient in PGLYRP1 (PGLYRP1 ${ }^{-/-}$), pathogen burden of experimentally infected mice were higher than wild-type in hearts and joints but not skin. Moreover, PGLYRP1 ${ }^{-/}$mice had reduced IgG serum levels and elevated proinflammatory cytokines (IFN- $\gamma$, CXCL9, CXCL10). The relationship between PGLYRP1 and pathophysiology of LD in humans is not yet known.

Phagocytic cells will attach to a spirochete via a repertoire of host cell surface receptors. These include Complement Receptor (CR) 3 and CD14 (197-200), urokinase receptors (uPAR) (200, 201), scavenger receptors such as macrophage receptor with collagenous structure (MARCO) (200, 202), some Toll-like receptors (TLRs), C-lectins, sialic acid-binding immunoglobulinlike receptors (siglecs), Fc receptors, or others (200). The attachment of $B b$ to host cell surface receptors leads to signaling that induces innate and specific adaptive immune responses, as well as clearance of the pathogen through phagocytosis. For example, the host cell surface receptor, Toll-like receptor 2 (TLR2), is a PRR that binds to ligands on the $B b$ cell surface that display certain pathogen associated molecular patterns (PAMPs). When a PRR senses a pathogenic ligand, it upregulates an inflammatory response, which commonly includes the induction of pro-inflammatory cytokines, chemokines, and antimicrobial peptides (AMPs); however, different types of activated PRRs induce different gene expression patterns. The production of proinflammatory cytokines, such as interleukin-6 (IL-6), recruits blood cells to the site of inflammation and induces the production of APPs, such as C-reactive protein (CRP).

The internalization and degradation of engulfed $B b$ spirochetes is sensed by intracellular receptors, including the NOD-like receptors (NLRs) and endosomal TLRs. These receptors activate signaling pathways that induce the production 
of cytokines, including interferons (IFNs). These are classified into three main types: I (IFN- $\alpha$ or IFN- $\beta$ ), II (IFN- $\gamma$ ), and III (IFN- $\lambda$ ) [(203), reviewed in (204), reviewed in (205)]. Type I IFNs are induced by $B b$ DNA or RNA through TLR7 and TLR9 (203), as well as TLR8 in monocytes (206). Type II IFN is produced by innate lymphocytes, including natural killer cells (NK cells) and by T helper cells (Th) (207). In vitro, type III IFN is induced in peripheral blood mononuclear cells (PBMCs) through TLR7 by live spirochetes or purified $B b$ RNA (208), perhaps controlled by $B b$ plasmid lp36 (203). The role of the type III IFN pathway in disease pathogenesis has not been fully elucidated, although clinical isolates associated with disseminated disease produce stronger IFN responses (Type I and III) (203).

The early stages of LD show an elevation of inflammatory markers and immune mediators $(69,119,209,210)$. CRP is an APP that is used clinically as a marker of inflammation that may denote infection, malignancy or cell stress (211). Within a few hours of an infection or other stressor, cytokines secreted by immune cells will enter the bloodstream and cause the liver to secrete CRP. Generally, the normal range of CRP for healthy adults is $<10 \mathrm{mg} / \mathrm{L}$; moderate elevation is $10-100$ $\mathrm{mg} / \mathrm{L}$; and marked elevation is $>100 \mathrm{mg} / \mathrm{L}$ (212). A longitudinal assessment of CRP levels in serum samples from $44 \mathrm{LD}$ patients presenting with one or more EM lesions and followed for 2 years after treatment, showed a significant elevation of CRP prior to treatment and a rapid decline to control levels following treatment (209). Elevated levels of CRP at the pre-treatment visit were seen again in a larger study by the same group, along with 6 additional elevated markers, including CCL19, ferritin, fibrinogen, IFN- $\gamma$-induced protein 10 (IP-10), monokine induced by IFN- $\gamma$ (MIG), and serum amyloid A (SAA) (119). The first systematic study of APP levels in serum samples from patients at different stages of LD and healthy controls was recently conducted (210). Consistent with the previous studies, CRP levels were most elevated in patients with early localized (single EM, $n=18$ ) and early disseminated (multiple EMs, $n=$ 17) LD, with 33 and $71 \%$ of patients, respectively, having CRP levels $>10 \mathrm{mg} / \mathrm{L}$ (210). More recently, a proteomic analysis of serum proteins in $70 \mathrm{LD}$ patients with one or more EM lesions at the time of diagnosis, identified six proteins, including CRP, with significantly altered serum levels shared across two independent cohorts (69). The other five elevated proteins are APOA4, C9, CST6, PGLYRP2, and S100A9. Two independent studies have also shown that the chemokines, CXCL-9 and CXCL-10, both known to be associated with IFN- $\gamma$ production and thus a "TH-1 type" of immune response, are elevated at time of diagnosis in EM+ LD patients in the USA and Europe $(120,209)$. Among a European cohort, patients with symptoms at study entry had significantly higher levels of CXCL9 compared to patients without symptoms (120).

\section{Inflammation and Immune Dysregulation Among Patients With Persistent LD}

The immune profiles of LD patients with persistent health problems following antibiotic treatment are not consistent across well-characterized subgroups, however several potentially important immune mediators have emerged within subgroups. Next, we will review each of these.

\section{CRP in Patients With Persistent Symptoms Following Treatment}

The levels of CRP in other stages of LD (subsequent to early localized or early disseminated, as described above) and patients with persistent signs or symptoms following treatment are less consistent. Among patients with antibiotic-refractory LA ( $n=$ 11), $55 \%$ have serum CRP levels $>10 \mathrm{mg} / \mathrm{L}$ while patients with early neurologic, late neurologic, and antibiotic responsive LA showed no significant difference in CRP levels compared to controls. For patients with PTLD $(n=74), 15 \%$ had CRP levels $>10 \mathrm{mg} / \mathrm{L}$ compared to $4 \%$ of patients with LD that returned to health following treatment $(n=68)$ (210). For some diseases, such as cardiovascular disease, serum CRP in the range of 3$10 \mathrm{mg} / \mathrm{L}$ is considered of clinical value for understanding an underlying inflammatory process or stratifying risk in some patients (213-215). A significant proportion of both, antibioticrefractory Lyme arthritis $(73 \%, n=11)$ and PTLD $(55 \%, n=$ 74) patients have serum CRP levels in this range (210). While these data are suggestive of an ongoing inflammatory process in these two patient subgroups, more research is needed to better understand the role of CRP, along with other markers of inflammation, and the underlying mechanisms at work in affected patients.

\section{IFN- $\gamma$ and Antibiotic-Refractory LA Patients}

Antibiotic-refractory LA patients without evidence of an ongoing infection, show excessive IFN- $\gamma$ production. So far, this biomarker appears to be specific for LA as serum levels of IFN $-\gamma$ are not significantly elevated among EM+ LD patients at the time of presentation compared to controls, nor are levels of this cytokine significantly elevated in patients with PTLD (119). A recent study did a comparative analysis of synovial tissue from patients with LA, rheumatoid arthritis, and low inflammation osteoarthritis and found that LA is unique, showing elevated levels of IFN- $\gamma$ and IFN $\gamma$-producing T cells and NK cells in synovial fluid (216). This study also identified and characterized a population of fibroblast-like synoviocytes (FLS) that are hypothesized to be involved in mediating persistent inflammation. These cells, when activated by IFN- $\gamma$ ex vivo, expressed genes and pathways that overlapped with that seen in postinfectious LA synovial tissue (216). This suggests that the FLS are driving ongoing inflammation and suppressed wound healing in an IFN $\gamma$-dependent manner.

\section{CCL19 Among PTLD Patients}

The T-cell chemokine, CCL19, was associated with susceptibility to PTLD. In a recent study, sixty-four cytokines, chemokines, and inflammatory markers were measured in serum collected from 76 $\mathrm{EM}+\mathrm{LD}$ patients at six visits over 1 year. Eleven patients (14.5\%) went on to develop persistent symptoms that impacted daily functioning following treatment and were classified as having PTLD. Twenty-nine patients (38.2\%) had symptoms following treatment without a functional impact on daily living and 36 patients (47.37\%) returned to health. Patients with CCL19 above 
$111.67 \mathrm{pg} / \mathrm{ml}$ at the (1-month) visit were 12.6 times more likely to meet criteria for PTLD at the 6 and 12 months timepoints (119). In a murine model, CCL19 along with IL-23, were associated with a pathological $\mathrm{TH} 17$ response in experimental autoimmune encephalomyelitis (EAE) (217). However, it has not been fully assessed to which extent the TH17 pathway is induced in LD patients.

\section{IL-23 Among European PTLD Patients}

A cytokine, IL-23, associated with IL-17 production and thus “TH-17"-type responses, is elevated in early LD and remains so among many European patients that have persistent symptoms following treatment. Eighty-six EM+, untreated LD patients that enrolled in an antimicrobial drug trial in Europe and were followed longitudinally for a year after treatment and were assayed for 26 cytokines and chemokines at 4 time points. Among the patients studied, 45 had symptoms following treatment consistent with having PTLD. One cytokine (IL-23) and two chemokines (CXCL9 and, to a lesser extent, CXCL10) showed significant differences across groups. Most patients with detectable IL-23 levels at study entry went on to develop PTLD and IL-23 levels remained elevated in these patients with ongoing symptoms. The seven patients with the highest levels of IL$23(\geq 230 \mathrm{ng} / \mathrm{mL})$ all went on to develop PTLD. Thus, an aberrant TH17-related immune response might be contributing to symptoms in patients with elevated IL-23 (120). It is interesting to note that no significant difference was identified in serum levels of IL-23 among the longitudinal cohort of LD patients from the USA, while CCL19 was not noted to be significantly elevated in the European cohort $(119,120)$. One potential reason for these differences is the difference in the primary agents of LD in Europe and the USA: B. afzelii and B. garinii vs. Bb. However, the mechanisms underlying these and other differences between LD in North America and Europe remain poorly understood.

\section{Autoantigens and Self-Reactivity in LA Patients}

The origin of autoimmune disease (AD) in humans have previously been thought of as triggered by microbial infection, which may serve as a catalyst for development of responses to self-antigens [reviewed in (218)]. Several autoimmune diseases are associated with bacterial triggers, such as gastric autoimmunity and Guillain-Barré syndrome triggered by infection with $H$. pylori and $C$. jejuni, respectively [reviewed in (219)]. One proposed mechanism for possible LD-associated autoimmunity is the circumstance where sequence or structural homology between human and $B b$ proteins cause B- and T-cell receptors to cross-react with an epitope on a $B b$ protein (the intended target) and a human protein (the unintended target). This could lead to ongoing inflammation of tissue and has been most well-studied in patients with LA (220-228). Four selfproteins (autoantigens) recognized by CD4 T cells have recently been identified in LD patients with LA through the use of tandem mass spectrometry on peptides in complex with MHC class II receptors (HLA-DR) (229). The four autoantigens identified include peptides from endothelial cell growth factor (ECGF), apolipoprotein B-100 (apoB-100), matrix metalloproteinase-10 (MMP-10), and annexin A2 proteins. Autoreactivity to these self-proteins appear to be primarily associated with LD, except annexin A2, which was associated with other rheumatic diseases (228), and potentially, to severe COVID-19 (230). To-date, no specific autoantigens have been identified reliably in LD. For the autoantigens that have been identified, we currently do not know whether the observed autoreactivity is induced by the presence of specific $B b$ antigens.

\section{Persistence}

\section{Persistent Antigenic Debris}

Recent studies of $B b$ peptidoglycan have renewed interest in the potential roles this immunogenic macromolecule may play in LA and, more broadly, in disease pathogenesis. Peptidoglycan $(\mathrm{PG})$ is an essential biopolymer that acts like a molecular bag-surrounding the bacterial cytoplasm and preventing cell bursting due to osmotic pressure. The cell walls of virtually all bacteria contain PG, and chemical and structural conservation is apparent [reviewed in (231)]. Glycan strands, made up of the repeating disaccharide $\mathrm{N}$-acetyl-glucosamine and $\mathrm{N}$ acetylmuramic acid, are cross-linked by peptides composed of often alternating $\mathrm{L}$ and $\mathrm{D}$-amino acids. Deviations from this chemical and conformational arrangement are rare, which make PG a quintessential pathogen-associated molecular pattern (PAMP) [reviewed in $(232,233)]$. Recognition of bacterial peptidoglycans by innate immune system receptors [e.g., Tolllike receptors (TLRs), PG recognition proteins (PGRPs), and NOD proteins] leads to inflammation and the production of cytokines that can result in host tissue damage. Immune response(s) to bacterial PGs have been associated with symptoms of infections such as gonorrhea $(234,235)$, chronic gastritis, and pertussis (236). There has been some evidence for a potential role for peptidoglycan in several autoimmune diseases, including rheumatoid arthritis (237) and multiple sclerosis $(238,239)$.

The cell envelope of $B b$ contains a peptidoglycan $\left(\mathrm{PG}^{\mathrm{Bb}}\right)$ that so far appears to be chemically unique, but conserved amongst some spirochetes. For example, close Borreliae relatives in the Relapsing Fever clade and Treponema genus have been reported to possess L-Orn-type PG (240, 241). For bacteria to grow, divide, and ultimately cause disease, PG is continuously remodeledsmall muropeptide fragments are removed and replaced with multimers. Unlike many other bacteria, $B b$ lacks the genetic components necessary for recycling the excised muropeptide fragments back into the cytoplasm. Instead, muropeptides are shed during growth and accumulate in logarithmic fashion that correlates with spirochete density (102). Analysis of radiolabeled, PG-associated amino acid over time, indicates that $B b$ sheds $\sim 45 \%$ of its PG per generation (102). Despite the overall abundance $\mathrm{PG}$ shedding would cause, its role in $\mathrm{LD}$ pathogenesis remains to be fully elucidated.

$\mathrm{PG}^{\mathrm{Bb}}$ elicits an immune response in humans. This was first shown in 1990 when PG isolated from $B b$ was injected subcutaneously into the forearm of a volunteer, one of the co-authors of the report, who then experienced intense inflammation at the injection site for $72 \mathrm{~h}$ (242). Jutras et al. detected $\mathrm{PG}^{\mathrm{Bb}}$ in $94 \%$ of synovial fluid samples collected from 34 patients with LA (102). They also demonstrated the connection between $\mathrm{PG}^{\mathrm{Bb}}$ and disease pathogenesis through tail 
vein injection of $\mathrm{PG}^{\mathrm{Bb}}$ into mice and the subsequent observation of acute arthritis (102).

Much remains to be determined about the role of $\mathrm{PG}^{\mathrm{Bb}}$ in LA and, more broadly, in LD. For instance, are the PG remnants that of dead/dying bacteria following phagocytosis or antibiotic therapy or are they shed muropeptides? Transcript levels of Lysozyme-the human enzyme responsible for degrading PGare elevated in LA patient SF (216), so why isn't it working or is the substrate absent (polymeric PG vs. muropeptides). The fate of shed muropeptide fragments, or their dwell time in different anatomical sites, is not known. In fact, the exact chemical composition of released muropeptide(s) is yet to be determined. Since released muropeptides must contain L-Orn (102), one intriguing possibility is that PG chemistry affects the response and/or half-life in the human host. Do germline variants or differential expression of human PGLYRP1 impact the pathogenesis of LD? Clearly, much remains to be elucidated, but methods toward preventing the human responses to $\mathrm{PG}^{\mathrm{Bb}}$ or eliminating the lingering antigen entirely, are two attractive avenues of future therapy in patients with persistent $\mathrm{LD}$.

\section{Persistent Infection}

Like most bacteria, $B b$ are able to change their cellular phenotype in order to better survive in adverse conditions. $B b$ form persister cells, in vitro $(85,243)$ or when exposed to antibiotics [(243), bacterial "persistence' reviewed in $(244)$, reviewed in $(245,246)]$. The connection between persister cells, atypical morphological forms of $B b$ and disease pathogenesis in LD remains poorly understood [reviewed in (247)].

Antibiotic resistance vs. antibiotic tolerance. Generally speaking, the ability of bacteria to grow in the presence of an antibiotic indicates resistance of a specific nature. Whether the antibiotic targets bacterial protein or nucleic acid synthesis, cell wall synthesis or integrity, or a specific metabolic pathway, uninhibited growth in the presence of that antibiotic demonstrates that the bacteria have acquired the ability to counteract that drug. Resistance may be inherent in the genome, acquired by horizontal gene transfer, or produced by mutation. Pseudomonas aeruginosa, for example, possesses multiple operons that encode efflux pumps (248) and Mycobacterium tuberculosis has become resistant by virtue of mutations which, for example, prevent the inhibitors of cell wall synthesis from binding to their target enzyme $(249,250)$. Alternatively, bacteria may stunt their own replication in the presence of a bacteriostatic antibiotic, thus minimizing the effect. The latter is non-specific and can be referred to as antibiotic tolerance. $B b$ encodes an efflux pump system, but specific resistance to antibiotics has not been clearly demonstrated (251). The generation of slow-growing or non-growing "persister" cells in vitro is a wellestablished observation for multiple bacterial species $(252,253)$. $B b$, in particular, has been shown to tolerate multiple antibiotics $(85,243)$ and form persisters by a stochastic mechanism leading to a slow-growing phenotype (254). Persister cells in vivo have not been demonstrated. In natural infection, the ability of bacteria to establish dormancy is perhaps best exemplified by Mycobacterium tuberculosis. Such infections can be latent for years and often never result in fulminant disease; the entry into dormancy is likely influenced by hypoxia or other environmental stressors (255). Another pathogenic spirochete, Treponema pallidum, can enter a chronic dormant phase within the human host and reactivate as tertiary syphilis years after the primary infection (256). How or where T. pallidum persists is not known.

If entry into a dormant phase occurs in vivo, the possibility for bacteria to tolerate growth-inhibiting compounds is a legitimate possibility. B. burgdorferi may enter dormancy during long periods of nutrient deprivation within the tick or following treatment of a mammalian host with a bacteriostatic antibiotic such as doxycycline. The stress response of the bacteria to nutrient deprivation has been described (257) and this capability to survive harsh environments may well contribute to antibiotic tolerance as well (258).

$B b$ infection, in particular. The question of the effectiveness of antibiotic treatment for LD has been contentious among physicians and researchers for some time (91, 259-261). Among the challenges to determining if antimicrobial therapy is curative is the absence of reliable measures to determine that infection has been cleared from LD patients and the vague, non-specific symptoms with which patients present in PTLD $(30,106)$. The notion that spirochetes may persist in humans derives primarily from the proportion of patients who experience symptoms post-treatment $(107,262)$. A few studies have examined this phenomenon in humans-two in the U. S. [reviewed in (263)] and one in the Netherlands (264). For both studies in the USA, only patients that had been treated for acute (early) LD were included and the authors concluded that resolution of symptoms did not occur with a subsequent 90 -day treatment with antibiotics (265). While the Netherlands study also showed no significant difference between longer term treatment of patients with chronic symptoms and short-term therapy, the inclusion criteria were less stringent, potentially allowing patients without LD into the study. More recently, spirochetes were detected in post-mortem brain samples collected from a patient who previously was diagnosed and treated for $\mathrm{LD}$ and subsequently experienced chronic symptoms, including dementia (266).

Studies of persistence. To date, multiple studies in animals have shown that $B b$ spirochetes do persist following antibiotic treatment of a disseminated infection (267-269). Even in humans, rare evidence of possible persistence was gleaned from feeding uninfected ticks on a patient with PTLD (270). In this study, only $B b$ DNA was detected while attempts to visualize or culture viable spirochetes from the xenodiagnostic ticks were unsuccessful. As others have noted, without the recovery of metabolically active spirochetes, this experiment is suggestive but is not a clear demonstration of persistent infection in humans (271).

Evidence from experiments performed in mice and dogs reveals that spirochetes can persist in the mammalian host after the administration of antimicrobial drugs. In one study, dogs were treated with a 30-day course of amoxicillin or doxycycline 2 months after infection (267). Spirochetes were recovered from tissues in 3 of 12 dogs. Skin punch biopsy samples 
from nearly all dogs were PCR-positive for $B b$ after treatment. Interestingly, serum antibodies to $B b$ declined post-treatment, but after the dogs were kept 6 months in pathogen-free housing, their antibody titers rose, indicating recrudescence. Spirochetal persistence has been examined in mice using xenodiagnostic studies in which naïve ticks were placed on infected mice that received a course of antibiotics (272-274). Those ticks acquired spirochetes from the mice post-treatment, detected by fluorescent imaging $(272)$ or PCR $(273,274)$. Two of these studies examined the existence of persistent spirochetes as a function of the time elapsed prior to treatment $(273,274)$. Spirochetal DNA was more frequently detected in xenodiagnostic ticks (XT) that fed upon mice treated 4 months post-infection than from those treated 3 weeks post-infection. When XT that had acquired organisms from antibiotic-treated mice fed upon naïve mice, the mice harbored spirochetal DNA in multiple tissues (detected by PCR), but organisms could not be recovered by tissue culture. Finally, studies in primates have shown that morphologically intact spirochetes can persist following antibiotic treatment (268). In a subsequent study, not only were the spirochetes found intact after treatment, but were shown to be transcriptionally active and were detected in multiple tissues, including the brain and heart $(275,276)$. This is evidence to suggest that the organisms are not fully cleared and may be attenuated for infection or for recovery by tissue culture.

With rare exception (127), only $B b$ genetic material (DNA or RNA), antigen, or non-culturable spirochetes have been detected following antibiotic treatment of an established infection. In none of the aforementioned animal studies has the pathogen been recovered as indicated by spirochete replication in culture soon (1-2 weeks) after inoculation of the standard BSK medium with tissue or tick specimen. Some experts in the field have therefore surmised that the spirochetes are non-viable and therefore that the infection is not persistent $(103,271,277$, 278). Evidence of resurgence in mice that were evaluated a year after antibiotic treatment contradicts this notion of nonviability (269). In that study, the amount of $B b$ genetic material in each mouse was quantified and found to increase from a very low level a few months after treatment to levels as high as in untreated animals at 12 months after treatment, indicating that the spirochetes replicated. The $B b$ bacteria present after antibiotic treatment, which are metabolically active and appear to be capable of resurging in vivo or resuscitated under the right culture conditions have been deemed "viable, but nonculturable (VBNC)."

The VBNC state is not unique to $B b$, but rather, it is known to occur in over 100 other bacterial species studied to date (279). Entering dormancy of this "nonculturable" type is very common for bacterial pathogens $(280,281)$. The VBNC state has been characterized as a deeper state of dormancy than that of persister cells, observed in several Vibrio species, E. coli, Campylobacter, Burkholderia, Listeria, Salmonella, and Helicobacter (281-283).

Persistent infection with $B b$ is difficult to rule-in or out as an explanation for LD patients with ongoing symptoms due to the challenge of culturing viable spirochetes from human specimens except in the earliest stages of infection, prior to antibiotic treatment (21). The failure to reliably isolate metabolically active spirochetes from patients does not exclude the possibility that they exist in some patients with ongoing health problems.

\section{PREVENTION}

\section{Ecological Prevention}

In the USA, $B b$ is the most common vector-borne pathogen; LD comprises $62.6 \%$ of all vector-borne diseases and $81.2 \%$ of all tick-borne diseases (1). There is an increasing trend of new cases in counties and states neighboring high-incidence regions, indicating a spread of the pathogen and disease risk in new geographical areas (52). The current complexities around the diagnosis and treatment of LD and PTLD suggest a growing need for primary prevention and to understand the intricacies of the ecological factors that impact disease risk.

$\mathrm{LD}$ risk, and the broader goal of prevention of $\mathrm{LD}$, is commonly viewed through two lenses: an ecological approach that focuses on characteristics of the tick vector, its hosts and the pathogens it transmits; and a human behavior approach that examines how behaviors and attitudes of human individuals, such as frequency of outdoor activities or use of protective equipment, change risk to disease $(284,285)$. Indirect factors regarding host populations, abiotic conditions, and land use or land coverage have also been found to increase disease risk, yet the magnitude of impact or relation to tick encounters and infection risk is still not fully understood $(284,286)$.

Popular ecological preventative techniques gravitate around reduction of host populations, reduction of ticks, and reduction of pathogen infection in ticks or hosts. Popular humanbehavioral strategies include altering the risk of exposure of humans through behavioral changes associated with selfprotection, use of outdoor space, and modifications of the environment. White-footed mice are the primary reservoir for $B b$ and their density has been shown to affect LD risk (287-290). The culling of white-tailed deer is a common preventative technique, but research sheds doubt on the viability or practicality of mass culling, suggesting that the technique is only effective on islands or closed populations where complete elimination can be accomplished (291). Personal protective measures, including checking body for ticks and use of tick repellent are frequently promoted by government and public health agencies. Some of these measures have been shown to reduce disease risk, yet effectiveness may be as low as $20-40 \%$, with some practices like checking one's body for ticks being found ineffective (284, 292 , 293). One challenge to prevention is the fact that nymphal ticks are as small as a poppy seed, and their bites can easily go unnoticed. Land usage or cover has shown strong trends of being impactful on exposure to LD, but still being researched is the spatial scale of land usage (284). Questions of land use in residential spaces or neighborhoods are still being explored, as well as the human movement within those spaces (294).

Several research projects have been initiated to further explore LD prevention by minimizing infection risk. The Tick Project is undertaking an immense randomized control trial of effectiveness of Met52 fungal spray and Tick Control System rodent bait boxes for LD prevention across 24 neighborhoods in Dutchess County, New York, while also collecting and assessing 
data on the entomological and host population risk factors, tracking tick encounters, and documenting cases of LD and PTLD across these neighborhoods (295). New models are being created to predict the first incidences of LD in counties without any reported cases of LD based on abiotic and human behavior factors (296). Prediction models will need to account for climate change as a contributing factor to the expanding range of LD. In addition, there are still several gaps in our knowledge about effective preventative techniques that should be further studied: abiotic factors and the capability of predictive modeling, diversity of $B b$ strains in tick and host populations and its impact on disease risk, predator communities and their role on host communities, changing landscapes and urban spaces, and the costs, sustainability, and acceptability to the public of preventative techniques $(286,288,290,297)$.

\section{Human Vaccine}

There is an urgent need for a safe and effective human vaccine that targets multiple pathogenic Borreliella species and strains, or even more broadly, common co-infections. Currently, there is no human vaccine for LD commercially available in the USA. In 1998, the FDA licensed Lymerix, a recombinant Osp-A based vaccine for the prevention of $\mathrm{LD}$ in adults. The vaccine required three shots over two tick seasons and was reported to be $76 \%$ effective in the prevention of LD after the third shot (49). The mechanism of action of this and other Osp-A based vaccines is antibody-mediated blocking of the transmission of Borreliella spirochetes from infected ticks while feeding on a human host $(298,299)$. Public demand and acceptance of the vaccine was low for a variety of factors reviewed elsewhere (300-304) and Lymerix was pulled from the market by its manufacturer, Smith-Kline Beecham in 2002. Interest from industry waned and other efforts to develop Lyme vaccine candidates were also abandoned, including those by MedImmune, Baxter and Connaught Laboratories (300).

Twenty years after Lymerix, there are now multiple efforts underway to develop next-generation human vaccines for the prevention of $\mathrm{LD}$. One challenge that these vaccines must address is the genetic diversity of pathogenic Borreliella species and strains across different geographies. Even a single infected tick may carry multiple heterologous strains of $\mathrm{Bb}$. Therefore, current vaccine candidates incorporate multiple immunogenic antigens or multiple serotypes of a single immunogenic antigen. Outer surface proteins, especially OspA-C, are the most common antigens selected among current human vaccine candidates, but other antigens and vaccine strategies are being studied [reviewed in (305)].

VLA15 is currently the only Lyme vaccine candidate in human trials. VLA15 uses recombinant outer surface protein A (OspA) from six different OspA serotypes of pathogenic Borreliella species, including $B b$ (OspA serotype 1), B. afzelii (OspA serotype 2), B. garinii (OspA serotypes 3, 5, 6), and $B$. bavariensis (OspA serotype 4) (306-308). In a similar approach, a prototype vaccine that uses bacterial ferritin nanoparticles fused with seven serotypes of OspA molecules from $B b, B$. afzelii, $B$. bavariensis and $B$. garinii recently showed durable high-titer antibody response in both mouse and rhesus macaque animal models (309). In both vaccine candidates, the antigenic residues in Osp-A serotype 1 that were previously suspected (221) but never shown to be cross-reactive were removed $(304,309)$.

There are several promising strategies for the development of other novel human vaccines for LD in experimental and preclinical stages. Marconi et al. has conducted studies in dogs on a subunit vaccine that includes OspA and at least 14 immunogenic linear epitopes ("chimeritope") from diverse isotypes of OspC. These outer surface proteins are expressed while $B b$ is in the tick gut (OspA) or during early human infection (OspC) [(305, 310-312), reviewed in (313)]. The OspC chimeritope is a component of the most widely used Lyme vaccine for dogs (314). By combining antigens that are expressed by Borreliella at different stages of infection, this vaccine has the potential to protect against spirochetes that are not blocked or killed while in the tick gut. This vaccine has not yet entered human trials. Another experimental vaccine targets Cspz, an outer surface protein involved in complement evasion (315).

The development of an anti-tick vaccine is one potential approach to protect people from multiple tick-borne diseases, including LD, as recently reviewed elsewhere (316). Ixodes scapularis ticks transmit 16 human pathogens (317) associated with tick-borne disease in the USA, including $B b$, Borrelia miyamotoi (318, 319), Babesia microti (320, 321), Anaplasma phagocytophilum (320, 322), Ehrlichia muris-like agent (EMLA) (323) and Powassan virus $(324,325)$. During transmission to a human, bacteria interact with tick proteins in the gut and salivary glands. These interactions can influence whether transmission occurs. Increased protection might be conferred if any of several steps in the transmission cycle are inhibited by targeting one or several of these tick proteins simultaneously. For example, mice that were given antiserum to the tick protein, Salp15, and then were challenged with $B b$, showed protection from colonization (326). Tick proteins may also elicit "tick immunity," a process during which a host becomes resistant to tick bites because the ticks cannot feed properly (327). If a vaccine can be developed that creates tick immunity in humans, this may enable the prevention of LD, and other tick-borne diseases, especially for those that migrate slowly from tick to human (305, 328-332). Viruses, such as Powassan, can be transmitted from tick to the human host in mere minutes. The attachment time required for tick-borne pathogens to migrate from tick to host was recently reviewed elsewhere (333). Encouragingly, there is already one commercially available tick vaccine used for the protection of livestock against tick infestation, though not including Ixodes spp. ticks (334-336).

\section{FIELD BUILDING}

To improve our ability to better address Lyme and other tickborne diseases, we need to attract researchers to the field and build shared resources that accelerate research progress such as biorepositories, genomic resources, animal models, and preclinical services (57). Interest in LD research over the past 5 years has remained relatively flat: the term "Lyme disease" is mentioned in around $\sim 1,000$ publications per year combined 
from PubMed Central in the USA and Europe. In this section, we describe several key resources for investigators seeking to study LD.

\section{Biorepositories and Research Cohorts}

Well-characterized samples are an essential tool to help researchers develop and validate new diagnostic tests and to better understand the complexities of LD. Well-characterized sample sets can benefit medical providers, test developers, and the public at risk for LD (337). It is critical that sample users understand the criteria used to enroll participants, how samples were collected and stored, and what additional clinical and testing data may be available. Additional benefits can be realized when multiple sample users (test developers and researchers) are using the same well-characterized sample sets. Current sample sets available for researchers include the CDC Lyme Serum Repository (LSR) (337), the Lyme Disease Biobank (23), and samples from the Studies of Lyme Immunology and Clinical Events (SLICE) at Johns Hopkins University School of Medicine. Additionally, some investigators also have their own sample collections with, in some cases, blood samples, skin biopsy specimens and synovial fluid which form the basis for collaborative studies $(69,102,338)$.

\section{Lyme Disease Biobank}

The Lyme Disease Biobank is a collection of more than 900 human biological samples that facilitates research in the field of $\mathrm{LD}$ and other tick-borne infections (TBI). Whole blood, serum and urine samples are collected from individuals presenting with the signs and symptoms of early LD with or without an EM lesion, individuals with later stages of $\mathrm{LD}$ including persistent $\mathrm{LD}$, and unaffected individuals (endemic controls). Samples have been collected from the East Coast, Upper Midwest, and California. Robust clinical information accompanies the samples, including information about symptoms, EM (if present), current medications, history of LD and other TBI, medical history, and demographics. Photographs of EM lesions are also taken (if present). Participants enrolled with early $L D$ also have the option of providing a convalescent sample 2-3 months after the initial blood draw. PCR testing is performed, in a blinded fashion, to confirm the presence of $B b$, Anaplasma phagocytophilum, Babesia microti, and B. miyamotoi in the samples. Serologic assays for standard two-tiered testing analysis (ELISA followed by IgM/ IgG Western immunoblotting) have also been performed. Each participant's donation provides samples for $\sim 50$ research projects, with aliquots of whole blood ( 1 and $2 \mathrm{ml})$, serum (250 $\mu \mathrm{l})$, and urine $(1 \mathrm{ml})$ available to sample users in academia and industry. More than 10,000 aliquots have been distributed across 50+ diagnostic research projects. The characterization of samples from 550 participants enrolled on the East Coast and Upper Midwest is detailed here (23). Specific panels are also available, including an unblinded panel for projects earlier in development, panels of later stages of LD including Lyme carditis and neuroborreliosis, panels of other TBI, as well as samples from patients with persistent LD. A tissue bank was recently launched for post-mortem and surgical samples. Tissue donors have the option to link their MyLymeData registry profile to their tissue sample $(339,340)$.

\section{Lyme Disease Research Center}

The primary focus of the Johns Hopkins Lyme Disease Research Center (LDRC) is clinical translational research to advance the fundamental understanding of LD through the characterization of carefully constructed cohorts of LD patients and controls, as well as a clinical biorepository of blood and tissue biospecimens. The LDRC enrolls participants from an expanded Mid-Atlantic region into a variety of research protocols, which all collect detailed health histories, clinical, and behavioral data. Over 350 participants have been enrolled in ongoing longitudinal cohort studies (some followed for up to 10 years), which include patients meeting CDC criteria for early and late $\mathrm{LD}$, as well as uninfected controls without $\mathrm{LD}$. An additional 275 participants meeting the IDSA definition for PTLD have also been enrolled in a clinical case series study (44). The SLICE studies obtain a number of different biosamples including: a skin biopsy (in patients with acute LD), whole blood, serum, plasma, PBMCs, DNA, RNA, skin and fecal swabs, and most recently, urine. All these samples are processed in the laboratory, aliquoted, archived and stored. Todate, they have shared $\sim 6,000$ sample aliquots for collaborative initiatives. The center collaborates with key investigators who utilize these samples for immune profiling (209), transcriptomics $(67,68)$, proteomics $(69)$, metabolomic $(75)$, and microbiomebased studies (58). These studies generate rich and deep clinical and molecular data sets that may allow for new insights into LD pathophysiology, lead to new diagnostic and therapeutic approaches, and have contributed to the characterization of LD and PTLD longitudinally across dozens of clinical and neurobehavioral variables. The LDRC has demonstrated that PTLD is a definable condition that is distinguishable from those that "return to health" following infection and treatment for LD. With the ability to compare PTLD patients with controls uninfected with LD, the SLICE studies show that the rates of individuals with both symptoms and a decline in health-related quality of life are significantly higher in patients previously treated for acute LD than in controls (14 vs. 4\%) (unpublished data). The growth of these cohorts over the years is also evidence that it is possible to not only recruit patients with PTLD into research, but also maintain their participation at high levels.

\section{Long Island Outdoor Worker Cohort}

To investigate the seasonal incidence and seroprevalence rates, a team of investigators at the Stony Brook School of Medicine assessed outdoor workers in the Hispanic/Latino immigrant population residing in Eastern Long Island and compared rates to those of non-immigrant outdoor workers. To further investigate occupational risk, they looked at differences of incidence rates in field workers and non-field workers within the Hispanic/Latino immigrant population. The study shows a significantly higher rate of $B b$ exposure among Hispanic/Latino immigrant field workers compared to those belonging to other occupations and in non-immigrant outdoor workers and also sheds light on the epidemiology, seroprevalence, and seasonal incidence of Lyme and other tick-borne diseases, as well as 
their clinical manifestations. Treatment and prevention of LD in this population can be especially difficult to obtain when multiple barriers are in place, such as poor health literacy, lack of preventative measures and limited access to healthcare in those with more risk. These findings underscore the necessity of improved education and preventative measures to better protect this vulnerable population $(341,342)$.

\section{Data Repositories LymeMIND Commons}

The LymeMIND center at the Icahn School of Medicine at Mount Sinai is developing LymeMIND Commons (https:// commons.lymemind.org/), an online database and a search engine that contains collected data and metadata integrated from the consortium and other LD resources. LymeMIND Commons enables researchers with the ability to find and analyze various types of data and metadata related to LD. Beyond transcriptomics, data includes protein arrays, methylation profiling by high throughput sequencing, genotyping, and other platforms. The metadata in LymeMIND Commons is JSON serialized and hosted using the Signature Commons platform. The metadata within LymeMIND Commons is linked to external ontologies and other resources for each study. In summary, LymeMIND Commons serves as a unique resource to advance $\mathrm{LD}$ research.

\section{DISCUSSION}

More research into the prevention, diagnosis and treatment of $\mathrm{LD}$ is needed in order to address the significant health risks posed by this tick-borne disease. The annual NIH and CDC investment in Lyme and tick-borne diseases research has been relatively unchanged for decades and is small compared to many other infectious diseases. In 2015, the Steven \& Alexandra Cohen Foundation established a research consortium involving over 30 leading universities, research laboratories and other organizations that aim to advance Lyme and tick-borne disease diagnosis and treatment, human vaccination, awareness and education, data science and management, and ecological

\section{REFERENCES}

1. Rosenberg R, Lindsey NP, Fischer M, Gregory CJ, Hinckley AF, Mead PS, et al. Vital signs: trends in reported vectorborne disease cases - United States and Territories, 2004-2016. MMWR Morb Mortal Wkly Rep. (2018) 67:496501. doi: 10.15585/mmwr.mm6717e1

2. Kugeler K, Schwartz A, Delorey M, Mead P, Hinckley A. Estimating the frequency of Lyme disease diagnoses, United States, 2010-2018. Emerg Infect Dis J. (2021) 27:616-9. doi: 10.3201/eid2702.202731

3. Nelson CA, Saha S, Kugeler KJ, Delorey MJ, Shankar MB, Hinckley AF, et al. Incidence of clinician-diagnosed Lyme disease, United States, 2005-2010. Emerg Infect Dis. (2015) 21:1625-31. doi: 10.3201/eid2109.150417

4. Steere AC, Strle F, Wormser GP, Hu LT, Branda JA, Hovius JWR, et al. Lyme borreliosis. Nat Rev Dis Primers. (2016) 2:16090. doi: 10.1038/nrdp.2016.90

5. Adrion ER, Aucott J, Lemke KW, Weiner JP. Health care costs, utilization and patterns of care following Lyme disease. PLOS ONE. (2015) 10:e0116767. doi: 10.1371/journal.pone.0116767 prevention. Philanthropic funding, including a new publicprivate partnership around novel diagnostic technologies, is critical to address the historically small amount of federal funding for LD compared to some other infectious disease of public health concern. While the Kay Hagan Tick Act did recently boost federal support for LD research (343), more is needed.

LD is a large topic. Some important advances were excluded for space considerations, such as immune evasion by $B b$ spirochetes, common co-infections, model organisms and in vitro systems for the study of $\mathrm{LD}$, neuronal sensitization hypothesis for the etiology of PTLD specifically and neuroborreliosis in general, among others.

In closing, in consideration of the unique global circumstances with the COVID-19 pandemic, it is important to highlight several features of the current context that may impact the LD community. For example, COVID-19 may further complicate diagnosis of LD since non-specific symptoms in these two conditions overlap and people may be spending more time outdoors. The emergence of a persistent syndrome, popularly referred to as long COVID, among a subset of patients following treatment or convalescence (344) may invigorate research and provide insights that carry-over into other infectious diseases with post-treatment sequelae, such as LD.

\section{AUTHOR CONTRIBUTIONS}

JRB wrote the first draft of the manuscript. BLJ, EJH, MEE, $A B$, and RLM wrote sections of the manuscript. All authors contributed to manuscript revision, read, and approved the submitted version.

\section{FUNDING}

All authors are supported by funding from the Steven \& Alexandra Cohen Foundation. Additional funding is provided by grants from the Global Lyme Alliance and NIH/NIAID R01AI157007 (NB); Bay Area Lyme Foundation (JRB); NIH R01 AI083640 (FY); NIAID/NIH R21AI133335 and R21AI142302 (RLM and PJR).
6. TBDWG. Tick-Borne Disease Working Group: Report to Congress 2018. HHS (2018). Available online at: https://www.hhs.gov/sites/default/files/tbdwgreport-to-congress-2018.pdf (accessed July 22, 2021).

7. Moon KA, Pollak J, Poulsen MN, Hirsch AG, DeWalle J, Heaney $\mathrm{CD}$, et al. Peridomestic and community-wide landscape risk factors for Lyme disease across a range of community contexts in Pennsylvania. Environ Res. (2019) 178:108649. doi: 10.1016/j.envres.2019. 108649

8. Nigrovic LE, Bennett JE, Balamuth F, Levas MN, Chenard RL, Maulden $\mathrm{AB}$, et al. Accuracy of clinician suspicion of Lyme disease in the emergency department. Pediatrics. (2017) 140:e20171975. doi: 10.1542/peds.2017-1975

9. Burlina PM, Joshi NJ, Mathew PA, Paul W, Rebman AW, Aucott JN. AI-based detection of erythema migrans and disambiguation against other skin lesions. Comput Biol Med. (2020) 125:103977. doi: 10.1016/j.compbiomed.2020.103977

10. Mead PS. Epidemiology of Lyme disease. Infect Dis Clin North Am. (2015) 29:187-210. doi: 10.1016/j.idc.2015.02.010 
11. Hirsch AG, Poulsen MN, Nordberg C, Moon KA, Rebman AW, Aucott JN, et al. Risk factors and outcomes of treatment delays in Lyme disease: a population-based retrospective cohort study. Front Med. (2020) 7:560018. doi: $10.3389 /$ fmed.2020.560018

12. Hirsch AG, Herman RJ, Rebman A, Moon KA, Aucott J, Heaney $\mathrm{C}$, et al. Obstacles to diagnosis and treatment of Lyme disease in the USA: a qualitative study. BMJ Open. (2018) 8:e021367. doi: 10.1136/bmjopen-2017-021367

13. Rebman AW, Bechtold KT, Yang T, Mihm EA, Soloski MJ, Novak CB, et al. The clinical, symptom, and quality-of-life characterization of a well-defined group of patients with posttreatment Lyme disease syndrome. Front Med. (2017) 4:224. doi: 10.3389/fmed.2017.00224

14. Johnson L, Aylward A, Stricker RB. Healthcare access and burden of care for patients with Lyme disease: a large United States survey. Health Policy. (2011) 102:64-71. doi: 10.1016/j.healthpol.2011.05.007

15. Tibbles CD, Edlow JA. Does this patient have erythema migrans? JAMA. (2007) 297:2617-27. doi: 10.1001/jama.297.23.2617

16. Diuk-Wasser MA, Hoen AG, Cislo P, Brinkerhoff R, Hamer SA, Rowland M, et al. Human risk of infection with Borrelia burgdorferi, the Lyme disease agent, in eastern United States. Am J Trop Med Hyg. (2012) 86:320-7. doi: 10.4269/ajtmh.2012.11-0395

17. Nieto NC, Porter WT, Wachara JC, Lowrey TJ, Martin L, Motyka PJ, et al. Using citizen science to describe the prevalence and distribution of tick bite and exposure to tick-borne diseases in the United States. PLoS ONE. (2018) 13:e0199644. doi: 10.1371/journal.pone.0199644

18. California Department of Public Health Vector-Borne Disease Section. Epidemiology and Prevention of Tick-Borne Diseases in California. Available online at: https://westnile.ca.gov/pdfs/ EpidemiologyandPreventionofTBDinCA.pdf (accessed July 7, 2021).

19. Centers for Disease Control and Prevention (CDC). Recommendations for test performance and interpretation from the Second National Conference on Serologic Diagnosis of Lyme Disease. MMWR Morb Mortal Wkly Rep. (1995) 44: 590-1.

20. Mead P, Petersen J, Hinckley A. Updated CDC recommendation for serologic diagnosis of Lyme disease. MMWR Morb Mortal Wkly Rep. (2019) 68:703. doi: 10.15585/mmwr.mm6832a4

21. Aguero-Rosenfeld ME, Wang G, Schwartz I, Wormser GP. Diagnosis of lyme borreliosis. Clin Microbiol Rev. (2005) 18:484-509. doi: 10.1128/CMR.18.3.484-509.2005

22. Theel ES. The past, present, and (possible) future of serologic testing for Lyme disease. J Clin Microbiol. (2016) 54:1191-6. doi: 10.1128/JCM. 03394-15

23. Horn EJ, Dempsey G, Schotthoefer AM, Prisco UL, McArdle M, Gervasi SS, et al. The Lyme disease biobank - characterization of 550 patient and control samples from the east coast and upper midwest of the United States. J Clin Microbiol. (2020) 58:26. doi: 10.1128/JCM.00032-20

24. Mosel MR, Rebman AW, Carolan HE, Montenegro T, Lovari R, Schutzer SE, et al. Molecular microbiological and immune characterization of a cohort of patients diagnosed with early Lyme disease. J Clin Microbiol. (2020) 59:e00615-20. doi: 10.1128/JCM.00615-20

25. Branda JA, Linskey K, Kim YA, Steere AC, Ferraro MJ. Two-tiered antibody testing for Lyme disease with use of 2 enzyme immunoassays, a wholecell sonicate enzyme immunoassay followed by a VlsE C6 peptide enzyme immunoassay. Clin Infect Dis. (2011) 53:541-7. doi: 10.1093/cid/cir464

26. Branda JA, Steere AC. Laboratory diagnosis of Lyme borreliosis. Clin Microbiol Rev. (2021) 34:e00018-19. doi: 10.1128/CMR.00018-19

27. Wormser GP, Nowakowski J, Nadelman RB, Visintainer P, Levin A, AgueroRosenfeld ME. Impact of clinical variables on Borrelia burgdorferi-specific antibody seropositivity in acute-phase sera from patients in North America with culture-confirmed early Lyme disease. Clin Vaccine Immunol. (2008) 15:1519-22. doi: 10.1128/CVI.00109-08

28. Steere AC, McHugh G, Damle N, Sikand VK. Prospective study of serologic tests for lyme disease. Clin Infect Dis. (2008) 47:188-95. doi: 10.1086/589242

29. Rebman AW, Crowder LA, Kirkpatrick A, Aucott JN. Characteristics of seroconversion and implications for diagnosis of post-treatment Lyme disease syndrome: acute and convalescent serology among a prospective cohort of early Lyme disease patients. Clin Rheumatol. (2015) 34:585-9. doi: $10.1007 /$ s10067-014-2706-Z
30. Rebman AW, Aucott JN. Post-treatment lyme disease as a model for persistent symptoms in Lyme disease. Front Med. (2020) 7:57. doi: 10.3389/fmed.2020.00057

31. Strobino B, Steinhagen K, Meyer W, Scheper T, Saschenbrecker S, Schlumberger W, et al. A community study of Borrelia burgdorferi antibodies among individuals with prior Lyme disease in endemic areas. Healthcare. (2018) 6:69. doi: 10.3390/healthcare6020069

32. Aguero-Rosenfeld ME. Lyme disease: laboratory issues. Infect Dis Clin North Am. (2008) 22:301-13, vii. doi: 10.1016/j.idc.2007.12.005

33. Seriburi V, Ndukwe N, Chang Z, Cox ME, Wormser GP. High frequency of false positive IgM immunoblots for Borrelia burgdorferi in clinical practice. Clin Microbiol Infect. (2012) 18:1236-40. doi: 10.1111/j.1469-0691.2011.03749.x

34. Eldin C, Raffetin A, Bouiller K, Hansmann Y, Roblot F, Raoult D, et al. Review of European and American guidelines for the diagnosis of Lyme borreliosis. Med Mal Infect. (2019) 49:121-32. doi: 10.1016/j.medmal.2018.11.011

35. Sanchez JL. Clinical manifestations and treatment of Lyme disease. Clin Lab Med. (2015) 35:765-78. doi: 10.1016/j.cll.2015.08.004

36. Pachner AR. Neurologic manifestations of lyme disease, the new "great imitator." Rev Infect Dis. (1989) 11:S1482-6. doi: 10.1093/clinids/11.Supplement_6.S1482

37. Fallon BA, Sotsky J, Brenner C, Makous M. Conquering Lyme Disease : Science Bridges the Great Divide with Columbia University Press. (2017). Available online at: https://books.google.com/books/about/Conquering Lyme_Disease.html?id=-Ds9DwAAQBAJ (accessed July 22, 2021).

38. Yeung C, Baranchuk A. Diagnosis and treatment of Lyme carditis: JACC review topic of the week. J Am Coll Cardiol. (2019) 73:717-26. doi: 10.1016/j.jacc.2018.11.035

39. Steere AC, Sikand VK, Schoen RT, Nowakowski J. Asymptomatic infection with Borrelia burgdorferi. Clin Infect Dis. (2003) 37:528-32. doi: $10.1086 / 376914$

40. Sigal LH. Toward a more complete appreciation of the clinical spectrum of Borrelia burgdorferi infection: early Lyme disease without erythema migrans. Am J Med. (2003) 114:74-5. doi: 10.1016/S0002-9343(02)01439-0

41. Carlsson H, Sandholm K, Haddish HW, Brudin L, Ekdahl KN, Tjernberg I. Complement activation in individuals with previous subclinical Lyme borreliosis and patients with previous Lyme neuroborreliosis. Eur J Clin Microbiol Infect Dis. (2019) 39:855-62. doi: 10.1007/s10096-019-03807-5

42. Kugeler KJ, Griffith KS, Gould LH, Kochanek K, Delorey MJ, Biggerstaff BJ, et al. A review of death certificates listing Lyme disease as a cause of death in the United States. Clin Infect Dis. (2011) 52:364-7. doi: 10.1093/cid/ciq157

43. Semproni M, Rusk R, Wuerz T. Fatal Lyme carditis presenting as fluctuating high-grade atrioventricular block. CMAJ. (2020) 192:E574-7. doi: $10.1503 / \mathrm{cmaj} .191194$

44. Wormser GP, Dattwyler RJ, Shapiro ED, Halperin JJ, Steere AC, Klempner MS, et al. The clinical assessment, treatment, and prevention of Lyme disease, human granulocytic anaplasmosis, and babesiosis: Clinical Practice Guidelines by the Infectious Diseases Society of America. Clin Infect Dis. (2006) 43:1089-134. doi: 10.1086/508667

45. Feder HM Jr, Whitaker DL. Misdiagnosis of erythema migrans. Am J Med. (1995) 99:412-9. doi: 10.1016/S0002-9343(99)80190-9

46. Aucott JN, Crowder LA, Yedlin V, Kortte KB. Bull's-eye and nontarget skin lesions of Lyme disease: an internet survey of identification of erythema migrans. Dermatol Res Pract. (2012) 2012:451727. doi: 10.1155/2012/451727

47. Schutzer SE, Berger BW, Krueger JG, Eshoo MW, Ecker DJ, Aucott JN. Atypical erythema migrans in patients with PCR-positive lyme disease. Emerg Infect Dis J. (2013) 19:815. doi: 10.3201/eid1905.120796

48. Dennison R, Novak C, Rebman A, Venkatesan A, Aucott J. Lyme disease with erythema migrans and seventh nerve palsy in an African-American Man. Cureus. (2019) 11:e6509. doi: 10.7759/cureus.6509

49. Steere AC, Sikand VK, Meurice F, Parenti DL, Fikrig E, Schoen RT, et al. Vaccination against Lyme disease with recombinant Borrelia burgdorferi outer-surface lipoprotein a with adjuvant. N Engl J Med. (1998) 339:209-15. doi: 10.1056/NEJM199807233390401

50. Steere AC, Dhar A, Hernandez J, Fischer PA, Sikand VK, Schoen RT, et al. Systemic symptoms without erythema migrans as the presenting picture of early Lyme disease. Am J Med. (2003) 114:58-62. doi: 10.1016/S0002-9343(02)01440-7 
51. Aucott J, Morrison C, Munoz B, Rowe PC, Schwarzwalder A, West SK. Diagnostic challenges of early Lyme disease: lessons from a community case series. BMC Infect Dis. (2009) 9:79. doi: 10.1186/14712334-9-79

52. Schwartz AM, Hinckley AF, Mead PS, Hook SA, Kugeler KJ. Surveillance for Lyme Disease - United States, 2008-2015. MMWR Surveill Summ. (2017) 66:1-12. doi: 10.15585/mmwr.ss6622al

53. Lagier J-C, Edouard S, Pagnier I, Mediannikov O, Drancourt M, Raoult D. Current and past strategies for bacterial culture in clinical microbiology. Clin Microbiol Rev. (2015) 28:208-36. doi: 10.1128/CMR.00110-14

54. Franco-Duarte R, Cernáková L, Kadam S, Kaushik KS, Salehi B, Bevilacqua A, et al. Advances in chemical and biological methods to identify microorganisms-from past to present. Microorganisms. (2019) 7:130. doi: 10.3390/microorganisms7050130

55. Wormser GP. Hematogenous dissemination in early Lyme disease. Wien Klin Wochenschr. (2006) 118:634-7. doi: 10.1007/s00508-006-0688-9

56. Nowakowski J, McKenna D, Nadelman RB, Bittker S, Cooper D, Pavia $\mathrm{C}$, et al. Blood cultures for patients with extracutaneous manifestations of Lyme disease in the United States. Clin Infect Dis. (2009) 49:1733-5. doi: $10.1086 / 648076$

57. NIH Strategic Research Plan Addresses Growing Tickborne Diseases Threat. National Institutes of Health (NIH) (2019). Available online at: https://www.nih.gov/news-events/news-releases/nih-strategic-researchplan-addresses-growing-tickborne-diseases-threat (accessed January 14, 2020).

58. Morrissette M, Pitt N, González A, Strandwitz P, Caboni M, Rebman $\mathrm{AW}$, et al. A distinct microbiome signature in posttreatment Lyme disease patients. MBio. (2020) 11:e02310-20. doi: 10.1128/mBio. 02310-20

59. Fitzgerald BL, Graham B, Delorey MJ, Pegalajar-Jurado A, Islam $\mathrm{MN}$, Wormser GP, et al. Metabolic response in patients with posttreatment Lyme disease symptoms/syndrome. Clin Infect Dis. (2020). doi: $10.1093 / \mathrm{cid} / \mathrm{ciaa} 1455$. [Epub ahead of print].

60. Tokarz R, Mishra N, Tagliafierro T, Sameroff S, Caciula A, Chauhan L, et al. A multiplex serologic platform for diagnosis of tick-borne diseases. Sci Rep. (2018) 8:3158. doi: 10.1038/s41598-018-21349-2

61. Arumugam S, Nayak S, Williams T, di Santa Maria FS, Guedes MS, Chaves RC, et al. A multiplexed serologic test for diagnosis of Lyme disease for point-of-care use. J Clin Microbiol. (2019) 57:e01142-19. doi: 10.1128/JCM.01142-19

62. Joung H-A, Ballard ZS, Wu J, Tseng DK, Teshome H, Zhang L, et al. Pointof-care serodiagnostic test for early-stage Lyme disease using a multiplexed paper-based immunoassay and machine learning. ACS Nano. (2020) 14:22940. doi: 10.1021/acsnano.9b08151

63. Blauwkamp TA, Thair S, Rosen MJ, Blair L, Lindner MS, Vilfan ID, et al. Analytical and clinical validation of a microbial cell-free DNA sequencing test for infectious disease. Nat Microbiol. (2019) 4:663-74. doi: 10.1038/s41564-018-0349-6

64. Branda JA, Lemieux JE, Blair L, Ahmed AA, Hong DK, Bercovici S, et al. Detection of Borrelia burgdorferi cell-free DNA in human plasma samples for improved diagnosis of early Lyme borreliosis. Clin Infect Dis. (2020) ciaa858. doi: $10.1093 / \mathrm{cid} / \mathrm{ciaa} 858$

65. Mosel MR, Carolan HE, Rebman AW, Castro S, Massire C, Ecker DJ, et al. Molecular testing of serial blood specimens from patients with early lyme disease during treatment reveals changing coinfection with mixtures of Borrelia burgdorferi genotypes. Antimicrob Agents Chemother. (2019) 63:e00237-19. doi: 10.1128/AAC.00237-19

66. Magni R, Espina BH, Shah K, Lepene B, Mayuga C, Douglas TA, et al. Application of Nanotrap technology for high sensitivity measurement of urinary outer surface protein A carboxyl-terminus domain in early stage Lyme borreliosis. J Transl Med. (2015) 13:346. doi: 10.1186/s12967-015-0701-z

67. Bouquet J, Soloski MJ, Swei A, Cheadle C, Federman S, Billaud J-N, et al. Longitudinal transcriptome analysis reveals a sustained differential gene expression signature in patients treated for acute Lyme disease. MBio. (2016) 7:e00100-16. doi: 10.1128/mBio.00100-16

68. Ma'ayan A, Clarke D, Rebman A, Bailey A, Wojciechowicz M, Jenkins S, et al. Predicting lyme disease from patients' peripheral blood mononuclear cells profiled with RNA-sequencing. Front Immunol. (2021) 12:452. doi: 10.3389/fimmu.2021.636289

69. Zhou Y, Qin S, Sun M, Tang L, Yan X, Kim T-K, et al. Measurement of organ-specific and acute-phase blood protein levels in early Lyme disease. J Proteome Res. (2020) 19:346-59. doi: 10.1021/acs.jproteome.9b00569

70. Reifert J, Kamath K, Bozekowski J, Lis E, Horn EJ, Granger D, et al. Serum epitope repertoire analysis enables early detection of Lyme disease with improved sensitivity in an expandable multiplex format. J Clin Microbiol. (2020) 59:e01836-20. doi: 10.1128/JCM.01836-20

71. Emerson RO, DeWitt WS, Vignali M, Gravley J, Hu JK, Osborne EJ, et al. Immunosequencing identifies signatures of cytomegalovirus exposure history and HLA-mediated effects on the T cell repertoire. Nat Genet. (2017) 49:659-65. doi: 10.1038/ng.3822

72. Molins CR, Ashton LV, Wormser GP, Hess AM, Delorey MJ, Mahapatra S, et al. Development of a metabolic biosignature for detection of early Lyme disease. Clin Infect Dis. (2015) 60:1767-75. doi: 10.1093/cid/civ185

73. Li K, Naviaux JC, Bright AT, Wang L, Naviaux RK. A robust, single-injection method for targeted, broad-spectrum plasma metabolomics. Metabolomics. (2017) 13:122. doi: 10.1007/s11306-017-1264-1

74. Pegalajar-Jurado A, Fitzgerald BL, Islam MN, Belisle JT, Wormser GP, Waller $\mathrm{KS}$, et al. Identification of urine metabolites as biomarkers of early Lyme disease. Sci Rep. (2018) 8:12204. doi: 10.1038/s41598-018-29713-y

75. Fitzgerald BL, Molins CR, Islam MN, Graham B, Hove PR, Wormser GP, et al. Host metabolic response in early Lyme disease. J Proteome Res. (2020) 19:610-23. doi: 10.1021/acs.jproteome.9b00470

76. Callister SM, Jobe DA, Stuparic-Stancic A, Miyamasu M, Boyle J, Dattwyler RJ, et al. Detection of IFN- $\gamma$ secretion by $\mathrm{T}$ cells collected before and after successful treatment of early Lyme disease. Clin Infect Dis. (2016) 62:1235-41. doi: 10.1093/cid/ciw112

77. Burlina PM, Joshi NJ, Ng E, Billings SD, Rebman AW, Aucott JN. Automated detection of erythema migrans and other confounding skin lesions via deep learning. Comput Biol Med. (2019) 105:151-6. doi: 10.1016/j.compbiomed.2018.12.007

78. Sell MG, Alcorta DA, Padilla AE, Nollner DW, Hasenkampf NR, Lambert HS, et al. Visualizing Borrelia burgdorferi infection using a small-molecule imaging probe. J Clin Microbiol. (2021) 59:e0231320. doi: 10.1128/JCM.02313-20

79. Asch ES, Bujak DI, Weiss M, Peterson MG, Weinstein A. Lyme disease: an infectious and postinfectious syndrome. J Rheumatol. (1994) 21:454-61.

80. Shadick NA, Phillips CB, Logigian EL, Steere AC, Kaplan RF, Berardi VP, et al. The long-term clinical outcomes of Lyme disease. A populationbased retrospective cohort study. Ann Intern Med. (1994) 121:560-7. doi: 10.7326/0003-4819-121-8-199410150-00002

81. Moody KD, Adams RL, Barthold SW. Effectiveness of antimicrobial treatment against Borrelia burgdorferi infection in mice. Antimicrob Agents Chemother. (1994) 38:1567-72. doi: 10.1128/AAC.38.7.1567

82. Wormser GP, Nadelman RB, Dattwyler RJ, Dennis DT, Shapiro ED, Steere AC, et al. Practice guidelines for the treatment of Lyme disease. The Infectious Diseases Society of America. Clin Infect Dis. (2000) 31(Suppl. 1):1-14. doi: $10.1086 / 512462$

83. Lantos PM, Rumbaugh J, Bockenstedt LK, Falck-Ytter YT, Aguero-Rosenfeld ME, Auwaerter PG, et al. Clinical Practice Guidelines by the Infectious Diseases Society of America (IDSA), American Academy of Neurology (AAN), and American College of Rheumatology (ACR): 2020 Guidelines for the Prevention, Diagnosis and Treatment of Lyme Disease. Clin Infect Dis. (2020) 72:e1-e48. doi: 10.1093/cid/ciaa1215

84. Wu X, Sharma B, Niles S, O'Connor K, Schilling R, Matluck N, et al. Identifying vancomycin as an effective antibiotic for killing Borrelia burgdorferi. Antimicrob Agents Chemother. (2018) 62:e00237-19. doi: 10.1128/AAC.01201-18

85. Feng J, Wang T, Shi W, Zhang S, Sullivan D, Auwaerter PG, et al. Identification of novel activity against Borrelia burgdorferi persisters using an FDA approved drug library. Emerg Microbes Infect. (2014) 3:e49. doi: 10.1038/emi.2014.53

86. Feng J, Auwaerter PG, Zhang Y. Drug combinations against Borrelia burgdorferi persisters in vitro: eradication achieved by using daptomycin, cefoperazone and doxycycline. PLoS ONE. (2015) 10:e0117207. doi: 10.1371/journal.pone.0117207 
87. Feng J, Li T, Yee R, Yuan Y, Bai C, Cai M, et al. Stationary phase persister/biofilm microcolony of Borrelia burgdorferi causes more severe disease in a mouse model of Lyme arthritis: implications for understanding persistence, Post-treatment Lyme Disease Syndrome (PTLDS), and treatment failure. Discov Med. (2019) 27:125-38.

88. Feng J, Leone J, Schweig S, Zhang Y. Evaluation of natural and botanical medicines for activity against growing and non-growing forms of $B$. burgdorferi. Front Med. (2020) 7:6. doi: 10.3389/fmed.2020.00006

89. Zhang Y, Alvarez-Manzo H, Leone J, Schweig S, Zhang Y. Botanical medicines cryptolepis sanguinolenta, Artemisia annua, Scutellaria baicalensis, Polygonum cuspidatum, and Alchornea cordifolia demonstrate inhibitory activity against Babesia duncani. Front Cell Infect Microbiol. (2021) 11:624745. doi: 10.3389/fcimb.2021.624745

90. Feng J, Shi W, Miklossy J, Tauxe GM, McMeniman CJ, Zhang Y. Identification of essential oils with strong activity against stationary phase Borrelia burgdorferi. Antibiotics. (2018) 7:89. doi: 10.3390/antibiotics7040089

91. Feder HM, Johnson BJB, O'Connell S, Shapiro ED, Steere AC, Wormser GP, et al. A critical appraisal of "Chronic Lyme Disease." N Engl J Med. (2007) 357:1422-30. doi: 10.1056/NEJMra072023

92. State of Connecticut. Circular Letter \#12-32. (1976). Available online at: https://portal.ct.gov/-/media/Departments-and-Agencies/DPH/dph/ infectious_diseases/lyme/1976circularletterpdf.pdf?la=en (accessed July 22, 2021).

93. Barbour AG, Benach JL. Discovery of the Lyme disease agent. MBio. (2019) 10:e2166-19. doi: 10.1128/mBio.02166-19

94. Miller JB, Aucott JN. Stages of Lyme arthritis. J Clin Rheumatol. (2020). doi: 10.1097/RHU.0000000000001513. [Epub ahead of print].

95. Steere AC. Treatment of lyme arthritis. J Clin Rheumatol. (2019) 46:871-3. doi: 10.3899/jrheum.190320

96. Steere AC, Levin RE, Molloy PJ, Kalish RA, Abraham JH 3rd, Liu NY, et al. Treatment of Lyme arthritis. Arthritis Rheum. (1994) 37:878-88. doi: 10.1002/art.1780370616

97. Steere AC, Angelis SM. Therapy for Lyme arthritis: strategies for the treatment of antibiotic-refractory arthritis. Arthritis Rheum. (2006) 54:307986. doi: 10.1002/art.22131

98. Arvikar SL, Steere AC. Diagnosis and treatment of Lyme arthritis. Infect Dis Clin North Am. (2015) 29:269-80. doi: 10.1016/j.idc.2015.02.004

99. Horton DB, Taxter AJ, Davidow AL, Groh BP, Sherry DD, Rose CD. Intraarticular glucocorticoid injection as second-line treatment for Lyme arthritis in children. J Rheumatol. (2019) 46:952-9. doi: 10.3899/jrheum.180829

100. Stanek G, Wormser GP, Gray J, Strle F. Lyme borreliosis. Lancet. (2012) 379:461-73. doi: 10.1016/S0140-6736(11)60103-7

101. Lochhead RB, Strle K, Kim ND, Kohler MJ, Arvikar SL, Aversa JM, et al. MicroRNA expression shows inflammatory dysregulation and tumorlike proliferative responses in joints of patients with postinfectious Lyme arthritis. Arthritis Rheumatol. (2017) 69:1100-10. doi: 10.1002/art.40039

102. Jutras BL, Lochhead RB, Kloos ZA, Biboy J, Strle K, Booth CJ, et al. Borrelia burgdorferi peptidoglycan is a persistent antigen in patients with Lyme arthritis. Proc Natl Acad Sci USA. (2019) 116:13498-507. doi: 10.1073/pnas.1904170116

103. Bockenstedt LK, Gonzalez DG, Haberman AM, Belperron AA. Spirochete antigens persist near cartilage after murine Lyme borreliosis therapy. J Clin Invest. (2012) 122:2652-60. doi: 10.1172/JCI58813

104. Chandra AM, Keilp JG, Fallon BA. Correlates of perceived health-related quality of life in post-treatment Lyme encephalopathy. Psychosomatics. (2013) 54:552-9. doi: 10.1016/j.psym.2013.04.003

105. Johnson L, Wilcox S, Mankoff J, Stricker RB. Severity of chronic Lyme disease compared to other chronic conditions: a quality of life survey. PeerJ. (2014) 2:e322. doi: $10.7717 /$ peerj.322

106. Marques A. Chronic Lyme disease: a review. Infect Dis Clin North Am. (2008) 22:341-60, vii-viii. doi: 10.1016/j.idc.2007.12.011

107. Aucott JN, Crowder LA, Kortte KB. Development of a foundation for a case definition of post-treatment Lyme disease syndrome. Int J Infect Dis. (2013) 17:e443-9. doi: 10.1016/j.ijid.2013.01.008

108. Aucott JN. Posttreatment Lyme disease syndrome. Infect Dis Clin North Am. (2015) 29:309-23. doi: 10.1016/j.idc.2015.02.012
109. DeLong A, Hsu M, Kotsoris H. Estimation of cumulative number of posttreatment Lyme disease cases in the US, 2016 and 2020. BMC Public Health. (2019) 19:352. doi: 10.1186/s12889-019-6681-9

110. Steere AC, Hutchinson GJ, Rahn DW, Sigal LH, Craft JE, DeSanna ET, et al. Treatment of the early manifestations of Lyme disease. Ann Intern Med. (1983) 99:22-6. doi: 10.7326/0003-4819-99-1-22

111. Dattwyler RJ, Halperin JJ. Failure of tetracycline therapy in early Lyme disease. Arthritis Rheum. (1987) 30:448-50. doi: 10.1002/art.1780300414

112. Donta ST. Tetracycline therapy for chronic Lyme disease. Clin Infect Dis. (1997) 25(Suppl. 1):S52-6. doi: 10.1086/516171

113. Shadick NA, Phillips CB, Sangha O, Logigian EL, Kaplan RF, Wright EA, et al. Musculoskeletal and neurologic outcomes in patients with previously treated Lyme disease. Ann Intern Med. (1999) 131:919-26. doi: 10.7326/0003-4819-131-12-199912210-00003

114. Kaplan RF, Trevino RP, Johnson GM, Levy L, Dornbush R, Hu LT, et al. Cognitive function in post-treatment Lyme disease: do additional antibiotics help? Neurology. (2003) 60:1916-22. doi: 10.1212/01.WNL.0000068030.26992.25

115. Bechtold KT, Rebman AW, Crowder LA, Johnson-Greene D, Aucott JN. Standardized symptom measurement of individuals with early Lyme disease over time. Arch Clin Neuropsychol. (2017) 32:129-41. doi: 10.1093/arclin/acw098

116. Horowitz RI, Freeman PR. Precision medicine: the role of the MSIDS model in defining, diagnosing, and treating chronic Lyme disease/Post Treatment Lyme Disease Syndrome and Other Chronic Illness: Part 2. Healthcare. (2018) 6:129. doi: 10.3390/healthcare6040129

117. Shor S, Green C, Szantyr B, Phillips S, Liegner K, Burrascano JJ Jr, et al. Chronic Lyme disease: an evidence-based definition by the ILADS Working Group. Antibiotics. (2019) 8:269. doi: 10.3390/antibiotics8040269

118. Rebman AW, Yang T, Aucott JN. Symptom heterogeneity and patient subgroup classification among US patients with post-treatment Lyme disease: an observational study. BMJ Open. (2021) 11:e040399. doi: 10.1136/bmjopen-2020-040399

119. Aucott JN, Soloski MJ, Rebman AW, Crowder LA, Lahey LJ, Wagner CA, et al. CCL19 as a chemokine risk factor for posttreatment Lyme disease syndrome: a prospective clinical cohort study. Clin Vaccine Immunol. (2016) 23:757-66. doi: 10.1128/CVI.00071-16

120. Strle K, Stupica D, Drouin EE, Steere AC, Strle F. Elevated levels of IL-23 in a subset of patients with post-lyme disease symptoms following erythema migrans. Clin Infect Dis. (2014) 58:372-80. doi: 10.1093/cid/cit735

121. Blum LK, Adamska JZ, Martin DS, Rebman AW, Elliott SE, Cao RRL, et al. Robust B cell responses predict rapid resolution of Lyme disease. Front Immunol. (2018) 9:1634. doi: 10.3389/fimmu.2018.01634

122. Stanek G, Reiter M. The expanding Lyme Borrelia complex-clinical significance of genomic species? Clin Microbiol Infect. (2011) 17:487-93. doi: 10.1111/j.1469-0691.2011.03492.x

123. Margos G, Fingerle V, Reynolds S. Borrelia bavariensis: vector switch, niche invasion, and geographical spread of a tick-borne bacterial parasite. Front Ecol Evol. (2019) 7:401. doi: 10.3389/fevo.2019.00401

124. Fingerle V, Schulte-Spechtel UC, Ruzic-Sabljic E, Leonhard S, Hofmann $\mathrm{H}$, Weber $\mathrm{K}$, et al. Epidemiological aspects and molecular characterization of Borrelia burgdorferi s.l. from southern Germany with special respect to the new species Borrelia spielmanii sp. nov. Int J Med Microbiol. (2008) 298:279-90. doi: 10.1016/j.ijmm.2007.05.002

125. Rudenko N, Golovchenko $M$, Ruzek D, Piskunova N, Mallátová N, Grubhoffer L. Molecular detection of Borrelia bissettii DNA in serum samples from patients in the Czech Republic with suspected borreliosis. FEMS Microbiol Lett. (2009) 292:274-81. doi: 10.1111/j.1574-6968.2009.01498.x

126. Girard YA, Fedorova N, Lane RS. Genetic diversity of Borrelia burgdorferi and detection of $B$. bissettii-like DNA in serum of north-coastal California residents. J Clin Microbiol. (2011) 49:945-54. doi: 10.1128/JCM.01689-10

127. Rudenko N, Golovchenko M, Vancova M, Clark K, Grubhoffer L, Oliver JH Jr. Isolation of live Borrelia burgdorferi sensu lato spirochaetes from patients with undefined disorders and symptoms not typical for Lyme borreliosis. Clin Microbiol Infect. (2016) 22:267.e9-15. doi: 10.1016/j.cmi.2015.11.009

128. Collares-Pereira M, Couceiro S, Franca I, Kurtenbach K, Schäfer SM, Vitorino L, et al. First isolation of Borrelia lusitaniae from a human patient. J Clin Microbiol. (2004) 42:1316-8. doi: 10.1128/JCM.42.3.1316-1318.2004 
129. de Carvalho IL, Fonseca JE, Marques JG, Ullmann A, Hojgaard A, Zeidner N, et al. Vasculitis-like syndrome associated with Borrelia lusitaniae infection. Clin Rheumatol. (2008) 27:1587-91. doi: 10.1007/s10067-008-1012-Z

130. Diza E, Papa A, Vezyri E, Tsounis S, Milonas I, Antoniadis A. Borrelia valaisiana in cerebrospinal fluid. Emerg Infect Dis. (2004) 10:1692-3. doi: 10.3201/eid1009.030439

131. Margos G, Sing A, Fingerle V. Published data do not support the notion that Borrelia valaisiana is human pathogenic. Infection. (2017) 45:567-9. doi: 10.1007/s15010-017-1032-1

132. Adeolu M, Gupta RS. A phylogenomic and molecular marker based proposal for the division of the genus Borrelia into two genera: the emended genus Borrelia containing only the members of the relapsing fever Borrelia, and the genus Borreliella gen. nov. containing the members of the Lyme disease Borrelia (Borrelia burgdorferi sensu lato complex). Antonie Van Leeuwenhoek. (2014) 105:1049-72. doi: 10.1007/s10482-014-0164-x

133. Barbour Ag. Borreliaceae. 1st ed. In: Whitman WB, Rainey F, Kämpfer P, Trujillo M, Chun J, DeVos P, et al., editors. Bergey's Manual of Systematics of Archaea and Bacteria. Hoboken, NJ: Wiley (2018). p. 1-22.

134. Cutler SJ. Relapsing fever borreliae: a global review. Clin Lab Med. (2015) 35:847-65. doi: 10.1016/j.cll.2015.07.001

135. Barbour AG, Adeolu M, Gupta RS. Division of the genus Borrelia into two genera (corresponding to Lyme disease and relapsing fever groups) reflects their genetic and phenotypic distinctiveness and will lead to a better understanding of these two groups of microbes (Margos et al.). There is inadequate evidence to support the division of the genus Borrelia. Int J Syst Evol Microbiol. (2017) 67:2058-67. doi: 10.1099/ijsem.0.001815

136. Margos G, Marosevic D, Cutler S, Derdakova M, Diuk-Wasser M, Emler S, et al. There is inadequate evidence to support the division of the genus Borrelia. Int J Syst Evol Microbiol. (2017) 67:1081-4. doi: 10.1099/ijsem.0.001717

137. Kingry LC, Anacker M, Pritt B, Bjork J, Respicio-Kingry L, Liu G, et al. Surveillance for and discovery of Borrelia Species in US Patients Suspected of Tickborne Illness. Clin Infect Dis. (2018) 66:1864-71. doi: 10.1093/cid/cix1107

138. Schotthoefer AM, Frost HM. Ecology and epidemiology of Lyme Borreliosis. Clin Lab Med. (2015) 35:723-43. doi: 10.1016/j.cll.2015.08.003

139. Rudenko N, Golovchenko M, Grubhoffer L, Oliver JH Jr. Updates on Borrelia burgdorferi sensu lato complex with respect to public health. Ticks Tick Borne Dis. (2011) 2:123-8. doi: 10.1016/j.ttbdis.2011.04.002

140. Wagemakers A, Staarink PJ, Sprong H, Hovius JWR. Borrelia miyamotoi: a widespread tick-borne relapsing fever spirochete. Trends Parasitol. (2015) 31:260-9. doi: 10.1016/j.pt.2015.03.008

141. Pritt BS, Mead PS, Johnson DKH, Neitzel DF, Respicio-Kingry LB, Davis JP, et al. Identification of a novel pathogenic Borrelia species causing Lyme borreliosis with unusually high spirochaetaemia: a descriptive study. Lancet Infect Dis. (2016) 16:556-64. doi: 10.1016/S1473-3099(15)00464-8

142. Kingry LC, Batra D, Replogle A, Rowe LA, Pritt BS, Petersen JM. Whole genome sequence and comparative genomics of the novel Lyme Borreliosis causing pathogen, Borrelia mayonii. PLoS ONE. (2016) 11:e0168994. doi: 10.1371/journal.pone.0168994

143. Schwartz I, Margos G, Casjens SR, Qiu W-G, Eggers CH. Multipartite genome of lyme disease borrelia: structure, variation and prophages. Curr Issues Mol Biol. (2020) 42:409-54. doi: 10.21775/cimb.042.409

144. Fraser CM, Casjens S, Huang WM, Sutton GG, Clayton R, Lathigra R, et al. Genomic sequence of a Lyme disease spirochaete, Borrelia burgdorferi. Nature. (1997) 390:580-6. doi: 10.1038/37551

145. Casjens S, Palmer N, van Vugt R, Huang WM, Stevenson B, Rosa $\mathrm{P}$, et al. A bacterial genome in flux: the twelve linear and nine circular extrachromosomal DNAs in an infectious isolate of the Lyme disease spirochete Borrelia burgdorferi. Mol Microbiol. (2000) 35:490-516. doi: 10.1046/j.1365-2958.2000.01698.x

146. Schutzer SE, Fraser-Liggett CM, Casjens SR, Qiu W-G, Dunn JJ, Mongodin $\mathrm{EF}$, et al. Whole-genome sequences of thirteen isolates of Borrelia burgdorferi. J Bacteriol. (2011) 193:1018-20. doi: 10.1128/JB.01158-10

147. Jabbari N, Glusman G, Joesch-Cohen LM, Reddy PJ, Moritz RL, Hood L, et al. Whole genome sequence and comparative analysis of Borrelia burgdorferi MM1. PLoS ONE. (2018) 13:e0198135. doi: 10.1371/journal.pone. 0198135
148. Tyler S, Tyson S, Dibernardo A, Drebot M, Feil EJ, Graham M, et al. Whole genome sequencing and phylogenetic analysis of strains of the agent of Lyme disease Borrelia burgdorferi from Canadian emergence zones. Sci Rep. (2018) 8:10552. doi: 10.1038/s41598-018-28908-7

149. Di L, Pagan PE, Packer D, Martin CL, Akther S, Ramrattan G, et al. BorreliaBase: a phylogeny-centered browser of Borrelia genomes. BMC Bioinformatics. (2014) 15:233. doi: 10.1186/1471-2105-15-233

150. Di L, Wan Z, Akther S, Ying C, Larracuente A, Li L, et al. Genotyping and quantifying lyme pathogen strains by deep sequencing of the outer surface protein C (ospC) locus. J Clin Microbiol. (2018) 56:e00940-18. doi: 10.1128/JCM.00940-18

151. Casjens SR, Di L, Akther S, Mongodin EF, Luft BJ, Schutzer SE, et al. Primordial origin and diversification of plasmids in Lyme disease agent bacteria. BMC Genomics. (2018) 19:218. doi: 10.1186/s12864-018-4597-X

152. Margos G, Hepner S, Mang C, Marosevic D, Reynolds SE, Krebs S, et al. Lost in plasmids: next generation sequencing and the complex genome of the tick-borne pathogen Borrelia burgdorferi. BMC Genomics. (2017) 18:422. doi: 10.1186/s12864-017-3804-5

153. Mongodin EF, Casjens SR, Bruno JF, Xu Y, Drabek EF, Riley DR, et al. Inter- and intra-specific pan-genomes of Borrelia burgdorferi sensu lato: genome stability and adaptive radiation. BMC Genomics. (2013) 14:693. doi: 10.1186/1471-2164-14-693

154. Hanincova K, Mukherjee P, Ogden NH, Margos G, Wormser GP, Reed KD, et al. Multilocus sequence typing of Borrelia burgdorferi suggests existence of lineages with differential pathogenic properties in humans. PLoS ONE. (2013) 8:e73066. doi: 10.1371/journal.pone.0073066

155. Wang G, Liveris D, Mukherjee P, Jungnick S, Margos G, Schwartz I. Molecular typing of Borrelia burgdorferi. Curr Protoc Microbiol. (2014) 34:12C.5.1-31. doi: 10.1002/9780471729259.mc12c05s34

156. Cerar T, Strle F, Stupica D, Ruzic-Sabljic E, McHugh G, Steere AC, et al. Differences in genotype, clinical features, and inflammatory potential of Borrelia burgdorferi sensu stricto Strains from Europe and the United States. Emerg Infect Dis. (2016) 22:818-27. doi: 10.3201/eid2205.151806

157. Lin Y-P, Benoit V, Yang X, Martínez-Herranz R, Pal U, Leong JM. Strainspecific variation of the decorin-binding adhesin DbpA influences the tissue tropism of the lyme disease spirochete. PLoS Pathog. (2014) 10:e1004238. doi: 10.1371/journal.ppat.1004238

158. Troy EB, Lin T, Gao L, Lazinski DW, Lundt M, Camilli A, et al. Global Tn-seq analysis of carbohydrate utilization and vertebrate infectivity of Borrelia burgdorferi. Mol Microbiol. (2016) 101:1003-23. doi: 10.1111/mmi. 13437

159. Ramsey ME, Hyde JA, Medina-Perez DN, Lin T, Gao L, Lundt $\mathrm{ME}$, et al. A high-throughput genetic screen identifies previously uncharacterized Borrelia burgdorferi genes important for resistance against reactive oxygen and nitrogen species. PLoS Pathog. (2017) 13:e1006225. doi: 10.1371/journal.ppat.1006225

160. Phelan JP, Kern A, Ramsey ME, Lundt ME, Sharma B, Lin T, et al. Genome-wide screen identifies novel genes required for Borrelia burgdorferi survival in its Ixodes tick vector. PLoS Pathog. (2019) 15:e1007644. doi: 10.1371/journal.ppat.1007644

161. Barbour AG, Jasinskas A, Kayala MA, Davies DH, Steere AC, Baldi P, et al. A genome-wide proteome array reveals a limited set of immunogens in natural infections of humans and white-footed mice with Borrelia burgdorferi. Infect Immun. (2008) 76:3374-89. doi: 10.1128/IAI.00048-08

162. Dowdell AS, Murphy MD, Azodi C, Swanson SK, Florens L, Chen S, et al. Comprehensive spatial analysis of the Borrelia burgdorferi lipoproteome reveals a compartmentalization bias toward the bacterial surface. J Bacteriol. (2017) 199:e00658-16. doi: 10.1128/JB.00658-16

163. Setubal JC, Reis M, Matsunaga J, Haake DA. Lipoprotein computational prediction in spirochaetal genomes. Microbiology. (2006) 152:113-21. doi: 10.1099/mic.0.28317-0

164. Burgdorfer W, Barbour AG, Hayes SF, Benach JL, Grunwaldt E, Davis JP. Lyme disease-a tick-borne spirochetosis? Science. (1982) 216:1317-9. doi: 10.1126/science.7043737

165. Talagrand-Reboul E, Westermann B, Raess MA, Schnell G, Cantero P, Barthel $\mathrm{C}$, et al. Proteomic as an exploratory approach to develop vaccines against tick-borne diseases using Lyme borreliosis as a test case. Vaccines. (2020) 8:463. doi: $10.3390 /$ vaccines 8030463 
166. Angel TE, Luft BJ, Yang X, Nicora CD, Camp DG 2nd, Jacobs JM, et al. Proteome analysis of Borrelia burgdorferi response to environmental change. PLoS ONE. (2010) 5:e13800. doi: 10.1371/journal.pone. 0013800

167. Schnell G, Boeuf A, Jaulhac B, Boulanger N, Collin E, Barthel C, et al. Proteomic analysis of three Borrelia burgdorferi sensu lato native species and disseminating clones: relevance for Lyme vaccine design. Proteomics. (2015) 15:1280-290. doi: 10.1002/pmic.201400177

168. Deutsch EW, Mendoza L, Shteynberg D, Slagel J, Sun Z, Moritz RL. Transproteomic pipeline, a standardized data processing pipeline for large-scale reproducible proteomics informatics. Proteomics Clin Appl. (2015) 9:745-54. doi: $10.1002 /$ prca.201400164

169. Tokarz R, Tagliafierro T, Sameroff S, Cucura DM, Oleynik A, Che $\mathrm{X}$, et al. Microbiome analysis of Ixodes scapularis ticks from New York and Connecticut. Ticks Tick Borne Dis. (2019) 10:894-900. doi: 10.1016/j.ttbdis.2019.04.011

170. Crowder CD, Matthews HE, Schutzer S, Rounds MA, Luft BJ, Nolte $\mathrm{O}$, et al. Genotypic variation and mixtures of Lyme Borrelia in Ixodes ticks from North America and Europe. PLoS ONE. (2010) 5:e10650. doi: 10.1371/journal.pone.0010650

171. Guttman DS, Wang PW, Wang IN, Bosler EM, Luft BJ, Dykhuizen DE. Multiple infections of Ixodes scapularis ticks by Borrelia burgdorferi as revealed by single-strand conformation polymorphism analysis. J Clin Microbiol. (1996) 34:652-6. doi: 10.1128/jcm.34.3.652-656.1996

172. Seinost G, Golde WT, Berger BW, Dunn JJ, Qiu D, Dunkin DS, et al. Infection with multiple strains of Borrelia burgdorferi sensu stricto in patients with Lyme disease. Arch Dermatol. (1999) 135:1329-33. doi: 10.1001/archderm.135.11.1329

173. Liveris D, Varde S, Iyer R, Koenig S, Bittker S, Cooper D, et al. Genetic diversity of Borrelia burgdorferi in lyme disease patients as determined by culture versus direct PCR with clinical specimens. J Clin Microbiol. (1999) 37:565-9. doi: 10.1128/JCM.37.3.565-569.1999

174. Keesing F, Brunner J, Duerr S, Killilea M, Logiudice K, Schmidt K, et al. Hosts as ecological traps for the vector of Lyme disease. Proc Biol Sci. (2009) 276:3911-9. doi: 10.1098/rspb.2009.1159

175. Stewart PE, Rosa PA. Physiologic and genetic factors influencing the zoonotic cycle of Borrelia burgdorferi. In: Adler B, editor. Spirochete Biology: The Post Genomic Era. Cham: Springer International Publishing (2018). p. 63-82.

176. Scoles GA, Papero M, Beati L, Fish D. A relapsing fever group spirochete transmitted by Ixodes scapularis ticks. Vector Borne Zoonotic Dis. (2001) 1:21-34. doi: 10.1089/153036601750137624

177. Rollend L, Fish D, Childs JE. Transovarial transmission of Borrelia spirochetes by Ixodes scapularis: a summary of the literature and recent observations. Ticks Tick Borne Dis. (2013) 4:46-51. doi: 10.1016/j.ttbdis.2012.06.008

178. Kurokawa C, Lynn GE, Pedra JHF, Pal U, Narasimhan S, Fikrig E. Interactions between Borrelia burgdorferi and ticks. Nat Rev Microbiol. (2020) 18:587-600. doi: 10.1038/s41579-020-0400-5

179. Ross BD, Hayes B, Radey MC, Lee X, Josek T, Bjork J, et al. Ixodes scapularis does not harbor a stable midgut microbiome. ISME J. (2018) 12:2596-607. doi: 10.1038/s41396-018-0161-6

180. Stewart PE, Bloom ME. Sharing the ride: ixodes scapularis symbionts and their interactions. Front Cell Infect Microbiol. (2020) 10:142. doi: $10.3389 /$ fcimb.2020.00142

181. Narasimhan S, Rajeevan N, Liu L, Zhao YO, Heisig J, Pan J, et al. Gut microbiota of the tick vector Ixodes scapularis modulate colonization of the Lyme disease spirochete. Cell Host Microbe. (2014) 15:58-71. doi: 10.1016/j.chom.2013.12.001

182. Landesman WJ, Mulder K, Fredericks LP, Allan BF. Cross-kingdom analysis of nymphal-stage Ixodes scapularis microbial communities in relation to Borrelia burgdorferi infection and load. FEMS Microbiol Ecol. (2019) 95:fiz167. doi: 10.1093/femsec/fiz167

183. Nuttall PA. Wonders of tick saliva. Ticks Tick Borne Dis. (2019) 10:470-81. doi: 10.1016/j.ttbdis.2018.11.005

184. Šimo L, Kazimirova M, Richardson J, Bonnet SI. The essential role of tick salivary glands and saliva in tick feeding and pathogen transmission. Front Cell Infect Microbiol. (2017) 7:281. doi: 10.3389/fcimb.2017. 00281
185. Wikel S. Ticks and tick-borne pathogens at the cutaneous interface: host defenses, tick countermeasures, and a suitable environment for pathogen establishment. Front Microbiol. (2013) 4:337. doi: 10.3389/fmicb.2013.00337

186. Vora A, Taank V, Dutta SM, Anderson JF, Fish D, Sonenshine DE, et al. Ticks elicit variable fibrinogenolytic activities upon feeding on hosts with different immune backgrounds. Sci Rep. (2017) 7:44593. doi: 10.1038/srep44593

187. Ribeiro JM, Mather TN. Ixodes scapularis: salivary kininase activity is a metallo dipeptidyl carboxypeptidase. Exp Parasitol. (1998) 89:213-21. doi: 10.1006/expr.1998.4296

188. Paesen GC, Adams PL, Nuttall PA, Stuart DL. Tick histamine-binding proteins: lipocalins with a second binding cavity. Biochim Biophys Acta. (2000) 1482:92-101. doi: 10.1016/S0167-4838(00)00168-0

189. Zhou W, Tahir F, Wang JC-Y, Woodson M, Sherman MB, Karim S, et al. Discovery of exosomes from tick saliva and salivary glands reveals therapeutic roles for CXCL12 and IL-8 in wound healing at the tick-human skin interface. Front Cell Dev Biol. (2020) 8:554. doi: 10.3389/fcell.2020.00554

190. Bernard Q, Gallo RL, Jaulhac B, Nakatsuji T, Luft B, Yang X, et al. Ixodes tick saliva suppresses the keratinocyte cytokine response to TLR2/TLR3 ligands during early exposure to Lyme borreliosis. Exp Dermatol. (2016) 25:26-31. doi: $10.1111 /$ exd.12853

191. Scholl DC, Embers ME, Caskey JR, Kaushal D, Mather TN, Buck WR, et al. Immunomodulatory effects of tick saliva on dermal cells exposed to Borrelia burgdorferi, the agent of Lyme disease. Parasit Vect. (2016) 9:394. doi: 10.1186/s13071-016-1638-7

192. Kim TK, Tirloni L, Pinto AFM, Moresco J, Yates JR III, da Silva Vaz I Jr, et al. Ixodes scapularis tick saliva proteins sequentially secreted every $24 \mathrm{~h}$ during blood feeding. PLoS Negl Trop Dis. (2016) 10:e0004323. doi: 10.1371/journal.pntd.0004323

193. Takeuchi O, Akira S. Pattern recognition receptors and inflammation. Cell. (2010) 140:805-20. doi: 10.1016/j.cell.2010.01.022

194. Salazar JC, Pope CD, Sellati TJ, Feder HM Jr, Kiely TG, Dardick KR, et al. Coevolution of markers of innate and adaptive immunity in skin and peripheral blood of patients with erythema migrans. J Immunol. (2003) 171:2660-70. doi: 10.4049/jimmunol.171.5.2660

195. Petnicki-Ocwieja T, Kern A. Mechanisms of Borrelia burgdorferi internalization and intracellular innate immune signaling. Front Cell Infect Microbiol. (2014) 4:175. doi: 10.3389/fcimb.2014.00175

196. Gupta A, Arora G, Rosen CE, Kloos Z, Cao Y, Cerny J, et al. A human secretome library screen reveals a role for peptidoglycan recognition protein 1 in Lyme borreliosis. PLoS Pathog. (2020) 16:e1009030. doi: 10.1371/journal.ppat.1009030

197. Hawley KL, Olson CM Jr, Iglesias-Pedraz JM, Navasa N, Cervantes JL, Caimano MJ, et al. CD14 cooperates with complement receptor 3 to mediate MyD88-independent phagocytosis of Borrelia burgdorferi. Proc Natl Acad Sci USA. (2012) 109:1228-32. doi: 10.1073/pnas.1112078109

198. Hawley KL, Martín-Ruiz I, Iglesias-Pedraz JM, Berwin B, Anguita J. CD14 targets complement receptor 3 to lipid rafts during phagocytosis of Borrelia burgdorferi. Int J Biol Sci. (2013) 9:803-10. doi: 10.7150/ijbs.7136

199. Hawley KL, Olson CM Jr, Carreras-González A, Navasa N, Anguita J. Serum C3 enhances complement receptor 3-mediated phagocytosis of Borrelia burgdorferi. Int J Biol Sci. (2015) 11:1269-71. doi: 10.7150/ijbs.13395

200. Carreras-González A, Barriales D, Palacios A, Montesinos-Robledo M, Navasa N, Azkargorta M, et al. Regulation of macrophage activity by surface receptors contained within Borrelia burgdorferienriched phagosomal fractions. PLoS Pathog. (2019) 15:e1008163. doi: 10.1371/journal.ppat.1008163

201. Hovius JWR, Bijlsma MF, van der Windt GJW, Wiersinga WJ, Boukens BJD, Coumou J, et al. The urokinase receptor (uPAR) facilitates clearance of Borrelia burgdorferi. PLoS Pathog. (2009) 5:e1000447. doi: 10.1371/journal.ppat.1000447

202. Petnicki-Ocwieja T, Chung E, Acosta DI, Ramos LT, Shin OS, Ghosh $\mathrm{S}$, et al. TRIF mediates Toll-like receptor 2-dependent inflammatory responses to Borrelia burgdorferi. Infect Immun. (2013) 81:402-10. doi: 10.1128/IAI.00890-12

203. Krupna-Gaylord MA, Liveris D, Love AC, Wormser GP, Schwartz I, Petzke MM. Induction of type I and type III interferons by Borrelia burgdorferi correlates with pathogenesis and requires linear plasmid 36. PLOS ONE. (2014) 9:e100174. doi: 10.1371/journal.pone.0100174 
204. Cohen TS, Parker D. Microbial pathogenesis and type III interferons. Cytokine Growth Factor Rev. (2016) 29:45-51. doi: 10.1016/j.cytogfr.2016.02.005

205. Syedbasha M, Egli A. Interferon lambda: modulating immunity in infectious diseases. Front Immunol. (2017) 8:119. doi: 10.3389/fimmu.2017.00119

206. Cervantes JL, La Vake CJ, Weinerman B, Luu S, O’Connell C, Verardi PH, et al. Human TLR8 is activated upon recognition of Borrelia burgdorferi RNA in the phagosome of human monocytes. J Leukoc Biol. (2013) 94:1231-41. doi: $10.1189 / \mathrm{jlb} .0413206$

207. Moore MW, Cruz AR, LaVake CJ, Marzo AL, Eggers CH, Salazar JC, et al. Phagocytosis of Borrelia burgdorferi and Treponema pallidum potentiates innate immune activation and induces gamma interferon production. Infect Immun. (2007) 75:2046-62. doi: 10.1128/IAI. 01666-06

208. Love AC, Schwartz I, Petzke MM. Borrelia burgdorferi RNA induces type I and III interferons via Toll-like receptor 7 and contributes to production of NF-kB-dependent cytokines. Infect Immun. (2014) 82:240516. doi: 10.1128/IAI.01617-14

209. Soloski MJ, Crowder LA, Lahey LJ, Wagner CA, Robinson WH, Aucott JN. Serum inflammatory mediators as markers of human Lyme disease activity. PLoS ONE. (2014) 9:e93243. doi: 10.1371/journal.pone.0093243

210. Uhde M, Ajamian M, Li X, Wormser GP, Marques A, Alaedini A. Expression of C-reactive protein and serum amyloid A in early to late manifestations of Lyme disease. Clin Infect Dis. (2016) 63:1399-404. doi: 10.1093/cid/ciw599

211. McPherson RA. Specific proteins. In: McPherson RA, Pincus MR, editors. Henry's Clinical Diagnosis and Management by Laboratory Methods. St. Louis, MO: Elsevier Health Sciences (2017). p. 25366.e2. Available online at: https://www.google.com/books/edition/Henry s_Clinical_Diagnosis_and_Managemen/xAzhCwAAQBAJ?hl=en (accessed July 22, 2021).

212. Nehring SM, Goyal A, Bansal P, Patel BC. C Reactive Protein (CRP). Treasure Island, FL: StatPearls Publishing (2020).

213. Kushner I, Rzewnicki D, Samols D. What does minor elevation of C-reactive protein signify? Am J Med. (2006) 119:166.e17-28. doi: 10.1016/j.amjmed.2005.06.057

214. Kushner I, Antonelli MJ. What should we regard as an "elevated" C-reactive protein level? Ann Intern Med. (2015) 163:326. doi: 10.7326/L15-5126

215. Greenland P, Alpert JS, Beller GA, Benjamin EJ, Budoff MJ, Fayad ZA, et al. 2010 ACCF/AHA guideline for assessment of cardiovascular risk in asymptomatic adults: a report of the American College of Cardiology Foundation/American Heart Association Task Force on Practice Guidelines. J Am Coll Cardiol. (2010) 56:e50-103. doi: 10.1016/j.jacc.2010.09.002

216. Lochhead RB, Arvikar SL, Aversa JM. Robust interferon signature and suppressed tissue repair gene expression in synovial tissue from patients with postinfectious, Borrelia burgdorferi-induced Lyme arthritis. Cell Microbiol. (2019) 21:e12954. doi: 10.1111/cmi.12954

217. Kuwabara T, Ishikawa $F$, Yasuda $T$, Aritomi K, Nakano H, Tanaka $\mathrm{Y}$, et al. CCR7 ligands are required for development of experimental autoimmune encephalomyelitis through generating IL-23-dependent Th17 cells. J Immunol. (2009) 183:2513-21. doi: 10.4049/jimmunol.0800729

218. Root-Bernstein R, Fairweather D. Complexities in the relationship between infection and autoimmunity. Curr Allergy Asthma Rep. (2014) 14:407. doi: 10.1007/s11882-013-0407-3

219. Badloe FMS, Janmohamed SR, Ring J, Gutermuth J. Microbial triggers in autoimmunity, severe allergy, and autoallergy. In: Schmidt-Weber CB, editor. Allergy Prevention and Exacerbation. Cham: Springer International Publishing (2017). p. 11-26.

220. Steere AC, Dwyer E, Winchester R. Association of chronic Lyme arthritis with HLA-DR4 and HLA-DR2 alleles. N Engl J Med. (1990) 323:219-23. doi: 10.1056/NEJM199007263230402

221. Gross DM, Forsthuber T, Tary-Lehmann M, Etling C, Ito K, Nagy ZA, et al. Identification of LFA-1 as a candidate autoantigen in treatment-resistant Lyme arthritis. Science. (1998) 281:703-6. doi: 10.1126/science.281.5377.703

222. Steere AC, Klitz W, Drouin EE, Falk BA, Kwok WW, Nepom GT, et al. Antibiotic-refractory Lyme arthritis is associated with HLA-DR molecules that bind a Borrelia burgdorferi peptide. J Exp Med. (2006) 203:961-71. doi: $10.1084 /$ jem. 20052471
223. Ghosh S, Seward R, Costello CE, Stollar BD, Huber BT. Autoantibodies from synovial lesions in chronic, antibiotic treatment-resistant Lyme arthritis bind cytokeratin-10. J Immunol. (2006) 177:2486-94. doi: 10.4049/jimmunol.177.4.2486

224. Drouin EE, Glickstein L, Kwok WW, Nepom GT, Steere AC. Human homologues of a Borrelia $\mathrm{T}$ cell epitope associated with antibiotic-refractory Lyme arthritis. Mol Immunol. (2008) 45:180-9. doi: 10.1016/j.molimm.2007.04.017

225. Seward RJ, Drouin EE, Steere AC, Costello CE. Peptides presented by HLADR molecules in synovia of patients with rheumatoid arthritis or antibioticrefractory Lyme arthritis. Mol Cell Proteomics. (2011) 10:M110.002477. doi: 10.1074/mcp.M110.002477

226. Londoño D, Cadavid D, Drouin EE, Strle K, McHugh G, Aversa JM, et al. Antibodies to endothelial cell growth factor and obliterative microvascular lesions in the synovium of patients with antibiotic-refractory lyme arthritis. Arthritis Rheumatol. (2014) 66:2124-33. doi: 10.1002/art.38618

227. Pianta A, Drouin EE, Crowley JT, Arvikar S, Strle K, Costello CE, et al. Annexin A2 is a target of autoimmune $\mathrm{T}$ and $\mathrm{B}$ cell responses associated with synovial fibroblast proliferation in patients with antibiotic-refractory Lyme arthritis. Clin Immunol. (2015) 160:336-41. doi: 10.1016/j.clim.2015.07.005

228. Sulka KB, Strle K, Crowley JT, Lochhead RB, Anthony R, Steere AC Correlation of Lyme disease-associated IgG4 autoantibodies with synovial pathology in antibiotic-refractory Lyme arthritis. Arthritis Rheumatol. (2018) 70:1835-46. doi: 10.1002/art.40566

229. Crowley JT, Strle K, Drouin EE, Pianta A, Arvikar SL, Wang Q, et al. Matrix metalloproteinase- 10 is a target of $\mathrm{T}$ and $\mathrm{B}$ cell responses that correlate with synovial pathology in patients with antibiotic-refractory Lyme arthritis. J Autoimmun. (2016) 69:24-37. doi: 10.1016/j.jaut.2016.02.005

230. Zuniga M, Gomes C, Carsons SE, Bender MT, Cotzia P, Miao QR, et al. Autoimmunity to the lung protective phospholipid-binding protein Annexin A2 predicts mortality among hospitalized COVID-19 patients. Eur Respir J. (2021) 2100918. doi: 10.1183/13993003.00918-2021

231. Dworkin J. The medium is the message: interspecies and interkingdom signaling by peptidoglycan and related bacterial glycans. Annu Rev Microbiol. (2014) 68:137-54. doi: 10.1146/annurev-micro-091213-112844

232. Wolf AJ, Underhill DM. Peptidoglycan recognition by the innate immune system. Nat Rev Immunol. (2018) 18:243-54. doi: 10.1038/nri.2017.136

233. Irazoki O, Hernandez SB, Cava F. Peptidoglycan muropeptides: release, perception, and functions as signaling molecules. Front Microbiol. (2019) 10:500. doi: 10.3389/fmicb.2019.00500

234. Chan JM, Dillard JP. Attention seeker: production, modification, and release of inflammatory peptidoglycan fragments in neisseria species. J Bacteriol. (2017) 199:e00354-17. doi: 10.1128/JB.00354-17

235. Wolf AJ, Reyes CN, Liang W, Becker C, Shimada K, Wheeler ML, et al. Hexokinase is an innate immune receptor for the detection of bacterial peptidoglycan. Cell. (2016) 166:624-36. doi: 10.1016/j.cell.2016.05.076

236. Boneca IG. The role of peptidoglycan in pathogenesis. Curr Opin Microbiol. (2005) 8:46-53. doi: 10.1016/j.mib.2004.12.008

237. Schrijver IA, Melief MJ, Markusse HM, Van Aelst I, Opdenakker G, Hazenberg MP, et al. Peptidoglycan from sterile human spleen induces T-cell proliferation and inflammatory mediators in rheumatoid arthritis patients and healthy subjects. Rheumatology. (2001) 40:438-46. doi: 10.1093/rheumatology/40.4.438

238. Schrijver IA, van Meurs M, Melief MJ, Wim Ang C, Buljevac D, Ravid R, et al. Bacterial peptidoglycan and immune reactivity in the central nervous system in multiple sclerosis. Brain. (2001) 124:1544-54. doi: 10.1093/brain/124.8.1544

239. Kriesel JD, Bhetariya P, Wang Z-M, Renner D, Palmer C, Fischer KF. Spectrum of microbial sequences and a bacterial cell wall antigen in primary demyelination brain specimens obtained from living patients. Sci Rep. (2019) 9:1387. doi: 10.1038/s41598-018-38198-8

240. Azuma I, Taniyama T, Yamamura Y, Yanagihara Y, Hattori Y. Chemical studies on the cell walls of Leptorspira biflexa strain Urawa and Treponema pallidum strain Reiter. Jpn J Microbiol. (1975) 19:45-51. doi: 10.1111/j.1348-0421.1975.tb00846.x

241. Yanagihara Y, Kamisango K, Yasuda S, Kobayashi S, Mifuchi I, Azuma I, et al. Chemical compositions of cell walls and polysaccharide 
fractions of spirochetes. Microbiol Immunol. (1984) 28:535-44. doi: 10.1111/j.1348-0421.1984.tb00706.x

242. Beck G, Benach JL, Habicht GS. Isolation, preliminary chemical characterization, and biological activity of Borrelia burgdorferi peptidoglycan. Biochem Biophys Res Commun. (1990) 167:89-95. doi: 10.1016/0006-291X(90)91734-A

243. Sharma B, Brown AV, Matluck NE, Hu LT, Lewis K. Borrelia burgdorferi, the causative agent of Lyme disease, forms drug-tolerant persister cells. Antimicrob Agents Chemother. (2015) 59:4616-24. doi: 10.1128/AAC.00864-15

244. Balaban NQ, Helaine S, Lewis K, Ackermann M, Aldridge B, Andersson DI, et al. Definitions and guidelines for research on antibiotic persistence. Nat Rev Microbiol. (2019) 17:441-8. doi: 10.1038/s41579-019-0207-4

245. Gollan B, Grabe G, Michaux C, Helaine S. Bacterial persisters and infection: past, present, and progressing. Annu Rev Microbiol. (2019) 73:359-85. doi: 10.1146/annurev-micro-020518-115650

246. Lewis K. (editor). Persister Cells and Infectious Disease (1st ed.). Switzerland: Springer (2019)

247. Lantos PM, Auwaerter PG, Wormser GP. A systematic review of Borrelia burgdorferi morphologic variants does not support a role in chronic Lyme disease. Clin Infect Dis. (2014) 58:663-71. doi: 10.1093/cid/cit810

248. Alvarez-Ortega C, Wiegand I, Olivares J, Hancock REW, Martínez JL. The intrinsic resistome of Pseudomonas aeruginosa to $\beta$-lactams. Virulence. (2011) 2:144-6. doi: 10.4161/viru.2.2.15014

249. Georghiou SB, Magana M, Garfein RS, Catanzaro DG, Catanzaro A, Rodwell TC. Evaluation of genetic mutations associated with Mycobacterium tuberculosis resistance to amikacin, kanamycin and capreomycin: a systematic review. PLoS ONE. (2012) 7:e33275. doi: 10.1371/journal.pone.0033275

250. Rattan A, Kalia A, Ahmad N. Multidrug-resistant Mycobacterium tuberculosis: molecular perspectives. Emerg Infect Dis. (1998) 4:195-209. doi: $10.3201 /$ eid0402.980207

251. Bunikis I, Denker K, Ostberg Y, Andersen C, Benz R, Bergström S. An RND-type efflux system in Borrelia burgdorferi is involved in virulence and resistance to antimicrobial compounds. PLoS Pathog. (2008) 4:e1000009. doi: 10.1371/journal.ppat.1000009

252. Lewis K. Persister cells, dormancy and infectious disease. Nat Rev Microbiol. (2007) 5:48-56. doi: 10.1038/nrmicro1557

253. Lewis K. Persister cells. Annu Rev Microbiol. (2010) 64:357-72. doi: 10.1146/annurev.micro.112408.134306

254. Caskey JR, Embers ME. Persister development by Borrelia burgdorferi populations in vitro. Antimicrob Agents Chemother. (2015) 59:6288-95. doi: 10.1128/AAC.00883-15

255. Gengenbacher M, Kaufmann SHE. Mycobacterium tuberculosis: success through dormancy. FEMS Microbiol Rev. (2012) 36:514-32. doi: 10.1111/j.1574-6976.2012.00331.x

256. Singh AE, Romanowski B. Syphilis: review with emphasis on clinical, epidemiologic, and some biologic features. Clin Microbiol Rev. (1999) 12:187-209. doi: 10.1128/CMR.12.2.187

257. Cabello FC, Godfrey HP, Bugrysheva JV, Newman SA. Sleeper cells: the stringent response and persistence in the Borreliella (Borrelia) burgdorferi enzootic cycle. Environ Microbiol. (2017) 19:3846-62. doi: $10.1111 / 1462-2920.13897$

258. Caskey JR, Hasenkampf NR, Martin DS, Chouljenko VN, Subramanian R, Cheslock MA, et al. The functional and molecular effects of doxycycline treatment on Borrelia burgdorferi phenotype. Front Microbiol. (2019) 10:690. doi: 10.3389/fmicb.2019.00690

259. Mayer L, Merz S. An appraisal of "chronic Lyme disease." New Engl J Med. (2008)358:428-31. doi: 10.1056/NEJMc0 73063

260. Stricker RB. Counterpoint: long-term antibiotic therapy improves persistent symptoms associated with lyme disease. Clin Infect Dis. (2007) 45:149-57. doi: $10.1086 / 518853$

261. Auwaerter PG. Point: antibiotic therapy is not the answer for patients with persisting symptoms attributable to lyme disease. Clin Infect Dis. (2007) 45:143-8. doi: 10.1086/518854

262. Aucott JN, Rebman AW, Crowder LA, Kortte KB. Post-treatment Lyme disease syndrome symptomatology and the impact on life functioning: is there something here? Qual Life Res. (2013) 22:75-84. doi: 10.1007/s11136-012-0126-6

263. Klempner MS. Controlled trials of antibiotic treatment in patients with posttreatment chronic Lyme disease. Vector Borne Zoonotic Dis. (2002) 2:255-63. doi: $10.1089 / 153036602321653842$

264. Berende A, ter Hofstede HJM, Vos FJ, van Middendorp H, Vogelaar ML, Tromp M, et al. Randomized trial of longer-term therapy for symptoms attributed to Lyme disease. N Engl J Med. (2016) 374:1209-20. doi: 10.1056/NEJMoa1505425

265. Klempner MS, Hu LT, Evans J, Schmid CH, Johnson GM, Trevino RP, et al. Two controlled trials of antibiotic treatment in patients with persistent symptoms and a history of Lyme disease. N Engl J Med. (2001) 345:85-92. doi: 10.1056/NEJM200107123450202

266. Embers M, Gadila S, Rosoklija G, Dwork A, Fallon B. Detection of Borrelia spirochetes in autopsy specimens: validation and a case study. Front Neurol. (2021) 12:707. doi: 10.3389/fneur.2021.628045

267. Straubinger RK, Summers BA, Chang YF, Appel MJ. Persistence of Borrelia burgdorferi in experimentally infected dogs after antibiotic treatment. J Clin Microbiol. (1997) 35:111-6. doi: 10.1128/jcm.35.1.111-116.1997

268. Embers ME, Barthold SW, Borda JT, Bowers L, Doyle L, Hodzic E, et al. Persistence of Borrelia burgdorferi in rhesus macaques following antibiotic treatment of disseminated infection. PLoS ONE. (2012) 7:e29914. doi: 10.1371/annotation/4cafed66-fb84-4589-a001-131d9c50aea6

269. Hodzic E, Imai D, Feng S, Barthold SW. Resurgence of persisting noncultivable Borrelia burgdorferi following antibiotic treatment in mice. PLoS ONE. (2014) 9:e86907. doi: 10.1371/journal.pone.0086907

270. Marques A, Telford SR, Turk S-P, Chung E, Williams C, Dardick K, et al. Xenodiagnosis to detect Borrelia burgdorferi infection: a first-in-human study. Clin Infect Dis. (2014) 58:937-45. doi: 10.1093/cid/cit939

271. Bockenstedt LK, Radolf JD. Xenodiagnosis for posttreatment Lyme disease syndrome: resolving the conundrum or adding to it? Clin Infect Dis. (2014) 58:946-8. doi: 10.1093/cid/cit942

272. Bockenstedt LK, Mao J, Hodzic E, Barthold SW, Fish D. Detection of attenuated, noninfectious spirochetes in Borrelia burgdorferi-infected mice after antibiotic treatment. J Infect Dis. (2002) 186:1430-7. doi: $10.1086 / 345284$

273. Hodzic E, Feng S, Holden K, Freet KJ, Barthold SW. Persistence of Borrelia burgdorferi following antibiotic treatment in mice. Antimicrob Agents Chemother. (2008) 52:1728-36. doi: 10.1128/AAC.01050-07

274. Barthold SW, Hodzic E, Imai DM, Feng S, Yang X, Luft BJ. Ineffectiveness of tigecycline against persistent Borrelia burgdorferi. Antimicrob Agents Chemother. (2010) 54:643-51. doi: 10.1128/AAC.00788-09

275. Embers ME, Hasenkampf NR, Jacobs MB, Tardo AC, Doyle-Meyers LA, Philipp MT, et al. Variable manifestations, diverse seroreactivity and post-treatment persistence in non-human primates exposed to Borrelia burgdorferi by tick feeding. PLoS ONE. (2017) 12:e0189071. doi: 10.1371/journal.pone.0189071

276. Crossland NA, Alvarez X, Embers ME. Late disseminated Lyme disease: associated pathology and spirochete persistence posttreatment in rhesus macaques. Am J Pathol. (2018) 188:672-82. doi: 10.1016/j.ajpath.2017.11.005

277. Barbour A. Remains of infection. J Clin Investig. (2012) 122:2344-6. doi: 10.1172/JCI63975

278. Wormser GP, Baker PJ, O'Connell S, Pachner AR, Schwartz I, Shapiro ED. Critical analysis of treatment trials of rhesus macaques infected with Borrelia burgdorferi reveals important flaws in experimental design. Vector Borne Zoon Dis. (2012) 12:535-8. doi: 10.1089/vbz.2012.1012

279. Ayrapetyan M, Williams T, Oliver JD. Relationship between the viable but nonculturable state and antibiotic persister cells. J Bacteriol. (2018) 200:e00249-18. doi: 10.1128/JB.00249-18

280. Ramamurthy T, Ghosh A, Pazhani GP, Shinoda S. Current perspectives on viable but non-culturable (VBNC) pathogenic bacteria. Front Public Health. (2014) 2:103. doi: 10.3389/fpubh.2014.00103

281. Li L, Mendis N, Trigui H, Oliver JD, Faucher SP. The importance of the viable but non-culturable state in human bacterial pathogens. Front Microbiol. (2014) 5:258. doi: 10.3389/fmicb.2014.00258

282. Rice SA, McDougald D, Kjelleberg S. Vibrio vulnificus: a physiological and genetic approach to the viable but nonculturable response. J Infect Chemother. (2000) 6:115-20. doi: 10.1007/PL00012150 
283. Orruño M, Kaberdin VR, Arana I. Survival strategies of Escherichia coli and Vibrio spp.: contribution of the viable but nonculturable phenotype to their stress-resistance and persistence in adverse environments. World J Microbiol Biotechnol. (2017) 33:45. doi: 10.1007/s11274-017-2218-5

284. Fischhoff IR, Keesing F, Ostfeld RS. Risk factors for bites and diseases associated with black-legged ticks: a meta-analysis. Am J Epidemiol. (2019) 188:1742-50. doi: 10.1093/aje/kwz130

285. Preventing tick bites. In: CDC. (2019). Available online at: https://www.cdc. gov/ticks/avoid/on_people.html (accessed June 12, 2019).

286. Beard CB. Lyme disease prevention and control - the way forward. Can Commun Dis Rep. (2014) 40:91-4. doi: 10.14745/ccdr.v40i05a04

287. Ostfeld RS, Levi T, Keesing F, Oggenfuss K, Canham CD. Tick-borne disease risk in a forest food web. Ecology. (2018) 99:1562-73. doi: 10.1002/ecy.2386

288. Kilpatrick AM, Dobson ADM, Levi T, Salkeld DJ, Swei A, Ginsberg HS, et al. Lyme disease ecology in a changing world: consensus, uncertainty and critical gaps for improving control. Philos Trans R Soc Lond B Biol Sci. (2017) 372:20160117. doi: 10.1098/rstb.2016.0117

289. Turney S, Gonzalez A, Millien V. The negative relationship between mammal host diversity and Lyme disease incidence strengthens through time. Ecology, (2014) 95:3244-50. doi: 10.1890/14-0980.1

290. Izac JR, Camire AC, Schuler EJA, Hatke AL, O'Bier NS, Oliver LD Jr, et al. Serologic evidence for the exposure of eastern coyotes (Canis latrans) in Pennsylvania to the tick-borne pathogens Borreliella burgdorferi and Anaplasma phagocytophilum. mSphere. (2020) 5:e00544-20. doi: $10.1128 / \mathrm{mSphere}$.00544-20

291. Kugeler KJ, Jordan RA, Schulze TL, Griffith KS, Mead PS. Will culling whitetailed deer prevent lyme disease? Zoonoses Public Health. (2016) 63:337-45. doi: 10.1111/zph.12245

292. Vázquez M, Muehlenbein C, Cartter M, Hayes EB, Ertel S, Shapiro ED. Effectiveness of personal protective measures to prevent Lyme disease. Emerg Infect Dis. (2008) 14:210-6. doi: 10.3201/eid1402.070725

293. Richardson M, Khouja C, Sutcliffe K. Interventions to prevent Lyme disease in humans: a systematic review. Prev Med Rep. (2019) 13:16-22. doi: 10.1016/j.pmedr.2018.11.004

294. Fischhoff IR, Bowden SE, Keesing F, Ostfeld RS. Systematic review and metaanalysis of tick-borne disease risk factors in residential yards, neighborhoods, and beyond. BMC Infect Dis. (2019) 19:861. doi: 10.1186/s12879-019-4484-3

295. Keesing F, Ostfeld RS. The tick project: testing environmental methods of preventing tick-borne diseases. Trends Parasitol. (2018) 34:447-50. doi: 10.1016/j.pt.2018.03.005

296. Bisanzio D, Fernández MP, Martello E, Reithinger R, Diuk-Wasser MA. Current and future spatiotemporal patterns of Lyme disease reporting in the Northeastern United States. JAMA Netw Open. (2020) 3:e200319. doi: 10.1001/jamanetworkopen.2020.0319

297. Ostfeld RS, Brunner JL. Climate change and Ixodes tick-borne diseases of humans. Philos Trans R Soc Lond B Biol Sci. (2015) 370:20140051. doi: 10.1098/rstb.2014.0051

298. Schwan TG, Piesman J, Golde WT, Dolan MC, Rosa PA. Induction of an outer surface protein on Borrelia burgdorferi during tick feeding. Proc Natl Acad Sci USA. (1995) 92:2909-13. doi: 10.1073/pnas.92.7.2909

299. de Silva AM, Telford SR 3rd, Brunet LR, Barthold SW, Fikrig E. Borrelia burgdorferi OspA is an arthropod-specific transmission-blocking Lyme disease vaccine. J Exp Med. (1996) 183:271-5. doi: 10.1084/jem. 183.1.271

300. Hanson MS, Edelman R. Progress and controversy surrounding vaccines against Lyme disease. Expert Rev Vaccines. (2003) 2:683-703. doi: 10.1586/14760584.2.5.683

301. Poland GA. Vaccines against Lyme disease: what happened and what lessons can we learn? Clin Infect Dis. (2011) 52(Suppl. 3):s253-8. doi: $10.1093 / \mathrm{cid} / \mathrm{ciq} 116$

302. Embers ME, Narasimhan S. Vaccination against Lyme disease: past, present, and future. Front Cell Infect Microbiol. (2013) 3:6. doi: $10.3389 /$ fcimb. 2013.00006

303. Willyard C. Resurrecting the "yuppie vaccine." Nat Med. (2014) 20:698-701. doi: $10.1038 / \mathrm{nm} 0714-698$

304. Shaffer L. Inner Workings: Lyme disease vaccines face familiar challenges, both societal and scientific. Proc Natl Acad Sci USA. (2019) 116:19214-7. doi: $10.1073 /$ pnas. 1913923116
305. Gomes-Solecki M, Arnaboldi PM, Backenson PB, Benach JL, Cooper CL, Dattwyler RJ, et al. Protective immunity and new vaccines for Lyme disease. Clin Infect Dis. (2019) 70:1768-73. doi: 10.1093/cid/ciz872

306. Comstedt P, Schüler W, Meinke A, Lundberg U. The novel Lyme borreliosis vaccine VLA15 shows broad protection against Borrelia species expressing six different OspA serotypes. PLoS ONE. (2017) 12:e0184357. doi: 10.1371/journal.pone.0184357

307. Alternative Schedule Study For VLA15, a Vaccine Candidate Against Lyme Borreliosis - Full Text View. ClinicalTrials.gov. Available online at: https:// clinicaltrials.gov/ct2/show/NCT03970733? recrs=abdf\&cond=Lyme\$+ $\$$ Disease\&draw=3\&rank=15 (accessed March 17, 2020).

308. Immunogenicity and Safety Study of a Vaccine Against Lyme Borreliosis, in Healthy Adults Aged 18 to 65 Years. Randomized, Controlled, Observer-blind Phase 2 Study. - Full Text View. ClinicalTrials.gov. Available online at: https:// clinicaltrials.gov/ct2/show/NCT03769194 (accessed March 17, 2020).

309. Kamp HD, Swanson KA, Wei RR, Dhal PK, Dharanipragada R, Kern A, et al. Design of a broadly reactive Lyme disease vaccine. NPJ Vaccines. (2020) 5:33. doi: 10.1038/s41541-020-0183-8

310. Izac JR, Oliver LD Jr, Earnhart CG, Marconi RT. Identification of a defined linear epitope in the OspA protein of the Lyme disease spirochetes that elicits bactericidal antibody responses: implications for vaccine development. Vaccine. (2017) 35:3178-85. doi: 10.1016/j.vaccine.2017.04.079

311. Izac JR, Camire AC, Earnhart CG, Embers ME, Funk RA, Breitschwerdt EB, et al. Analysis of the antigenic determinants of the OspC protein of the Lyme disease spirochetes: evidence that the $\mathrm{C} 10$ motif is not immunodominant or required to elicit bactericidal antibody responses. Vaccine. (2019) 37:2401-7. doi: 10.1016/j.vaccine.2019.02.007

312. Izac JR, O'Bier NS, Oliver LD Jr, Camire AC, Earnhart CG, LeBlanc Rhodes DV, et al. Development and optimization of OspC chimeritope vaccinogens for Lyme disease. Vaccine. (2020) 38:1915-24. doi: 10.1016/j.vaccine.2020.01.027

313. O’Bier NS, Hatke AL, Camire AC, Marconi RT. Human and veterinary vaccines for Lyme disease. Curr Issues Mol Biol. (2020) 42:191-222. doi: $10.21775 /$ cimb.042.191

314. Marconi RT, Garcia-Tapia D, Hoevers J, Honsberger N, King VL, Ritter $D$, et al. VANGUARD $R$ crLyme: A next generation Lyme disease vaccine that prevents B. burgdorferi infection in dogs. Vaccine X. (2020) 6:100079. doi: 10.1016/j.jvacx.2020.100079

315. Marcinkiewicz AL, Lieknina I, Kotelovica S, Yang X, Kraiczy P, Pal U, et al. Eliminating factor $\mathrm{H}$-binding activity of Borrelia burgdorferi CspZ combined with virus-like particle conjugation enhances its efficacy as a Lyme disease vaccine. Front Immunol. (2018) 9:181. doi: 10.3389/fimmu.2018.00181

316. Rego ROM, Trentelman JJA, Anguita J, Nijhof AM, Sprong H, Klempa B, et al. Counterattacking the tick bite: towards a rational design of anti-tick vaccines targeting pathogen transmission. Parasites Vectors. (2019) 12:229. doi: 10.1186/s13071-019-3468-x

317. Nelder MP, Russell CB, Sheehan NJ, Sander B, Moore S, Li Y, et al. Human pathogens associated with the blacklegged tick Ixodes scapularis: a systematic review. Parasit Vectors. (2016) 9:265. doi: 10.1186/s13071-016-1529-y

318. Crowder CD, Carolan HE, Rounds MA, Honig V, Mothes B, Haag $\mathrm{H}$, et al. Prevalence of Borrelia miyamotoi in Ixodes ticks in Europe and the United States. Emerg Infect Dis. (2014) 20:1678-82. doi: 10.3201/eid2010.131583

319. Krause PJ, Narasimhan S, Wormser GP, Barbour AG, Platonov AE, Brancato $\mathrm{J}$, et al. Borrelia miyamotoi sensu lato seroreactivity and seroprevalence in the northeastern United States. Emerg Infect Dis. (2014) 20:1183-90. doi: 10.3201/eid2007.131587

320. Prusinski MA, Kokas JE, Hukey KT, Kogut SJ, Lee J, Backenson PB. Prevalence of Borrelia burgdorferi (Spirochaetales: Spirochaetaceae), Anaplasma phagocytophilum (Rickettsiales: Anaplasmataceae), and Babesia microti (Piroplasmida: Babesiidae) in Ixodes scapularis (Acari: Ixodidae) collected from recreational lands in the Hudson Valley Region, New York State. J Med Entomol. (2014) 51:226-36. doi: 10.1603/ME13101

321. Gray EB, Herwaldt BL. Babesiosis Surveillance - United States, 2011-2015. MMWR Surveill Summ. (2019) 68:1-11. doi: 10.15585/mmwr.ss6806a1

322. Levin ML, Ross DE. Acquisition of different isolates of Anaplasma phagocytophilum by Ixodes scapularis from a model animal. Vector Borne Zoonotic Dis. (2004) 4:53-9. doi: 10.1089/153036604773082997 
323. Pritt BS, Sloan LM, Johnson DKH, Munderloh UG, Paskewitz SM, McElroy KM, et al. Emergence of a new pathogenic Ehrlichia species, Wisconsin and Minnesota, 2009. N Engl J Med. (2011) 365:422-9. doi: 10.1056/NEJMoa1010493

324. Anderson JF, Armstrong PM. Prevalence and genetic characterization of Powassan virus strains infecting Ixodes scapularis in Connecticut. Am J Trop Med Hyg. (2012) 87:754-9. doi: 10.4269/ajtmh.2012.12-0294

325. Dupuis AP II, Peters RJ, Prusinski MA, Falco RC, Ostfeld RS, Kramer LD. Isolation of deer tick virus (Powassan virus, lineage II) from Ixodes scapularis and detection of antibody in vertebrate hosts sampled in the Hudson Valley, New York State. Parasit Vectors. (2013) 6:185. doi: 10.1186/1756-3305-6-185

326. Dai J, Wang P, Adusumilli S, Booth CJ, Narasimhan S, Anguita J, et al. Antibodies against a tick protein, Salp15, protect mice from the Lyme disease agent. Cell Host Microbe. (2009) 6:482-92. doi: 10.1016/j.chom.2009.10.006

327. Wikel SK. Host immunity to ticks. Ann Rev Entomol. (1996) 41:1-22. doi: 10.1146/annurev.en.41.010196.000245

328. Murfin KE, Fikrig E. Tick bioactive molecules as novel therapeutics: beyond vaccine targets. Front Cell Infect Microbiol. (2017) 7:222. doi: $10.3389 /$ fcimb.2017.00222

329. Narasimhan S, Schuijt TJ, Abraham NM, Rajeevan N, Coumou J, Graham $\mathrm{M}$, et al. Modulation of the tick gut milieu by a secreted tick protein favors Borrelia burgdorferi colonization. Nat Commun. (2017) 8:184. doi: 10.1038/s41467-017-00208-0

330. Murfin KE, Kleinbard R, Aydin M, Salazar SA, Fikrig E. Borrelia burgdorferi chemotaxis toward tick protein Salp12 contributes to acquisition. Ticks Tick Borne Dis. (2019) 10:1124-34. doi: 10.1016/j.ttbdis.2019.06.002

331. Narasimhan S, Booth CJ, DePonte K, Wu M-J, Liang X, Mohanty S, et al. Host-specific expression of Ixodes scapularis salivary genes. Ticks Tick Borne Dis. (2019) 10:386-97. doi: 10.1016/j.ttbdis.2018.12.001

332. Narasimhan S, Kurokawa C, Diktas H, Strank NO, Cerný J, Murfin K, et al. Ixodes scapularis saliva components that elicit responses associated with acquired tick-resistance. Ticks Tick Borne Dis. (2020) 11:101369. doi: 10.1016/j.ttbdis.2019.101369

333. Eisen L. Pathogen transmission in relation to duration of attachment by Ixodes scapularis ticks. Ticks Tick Borne Dis. (2018) 9:535-42. doi: 10.1016/j.ttbdis.2018.01.002

334. de la Fuente J, Kocan KM. Advances in the identification and characterization of protective antigens for recombinant vaccines against tick infestations. Exp Rev Vaccines. (2003) 2:583-93. doi: 10.1586/14760584.2.4.583

335. Carreón D, de la Lastra JMP, Almazán C, Canales M, Ruiz-Fons F, Boadella M, et al. Vaccination with BM86, subolesin and akirin protective antigens for the control of tick infestations in white tailed deer and red deer. Vaccine. (2012) 30:273-9. doi: 10.1016/j.vaccine.2011. 10.099

336. Gortazar C, Diez-Delgado I, Barasona JA, Vicente J, De La Fuente J, Boadella M. The wild side of disease control at the wildlife-livestock-human interface: a review. Front Vet Sci. (2014) 1:27. doi: 10.3389/fvets.2014.00027

337. Molins CR, Sexton C, Young JW, Ashton LV, Pappert R, Beard CB, et al. Collection and characterization of samples for establishment of a serum repository for lyme disease diagnostic test development and evaluation. J Clin Microbiol. (2014) 52:3755-62. doi: 10.1128/JCM.01409-14

338. Marques A, Schwartz I, Wormser GP, Wang Y, Hornung RL, Demirkale CY, et al. Transcriptome assessment of erythema migrans skin lesions in patients with early Lyme disease reveals predominant interferon signaling. I Infect Dis. (2017) 217:158-67. doi: 10.1093/infdis/jix563

339. Johnson L, Shapiro M, Mankoff J, Johnson L, Shapiro M, Mankoff J. Removing the mask of average treatment effects in chronic Lyme disease research using big data and subgroup analysis. Healthc Pap. (2018) 6:124. doi: 10.3390/healthcare6040124

340. Johnson L, Shapiro M, Stricker RB, Vendrow J, Haddock J, Needell D. Antibiotic treatment response in chronic Lyme disease: why do some patients improve while others do not? Healthcare. (2020) 8:383. doi: 10.3390/healthcare8040383

341. Vilcarromero S, Nunez AM, Vivas K, Mahmood S, Russo J, Wellins A-M, et al. 1633. Human co-infection with Borrelia burgdorferi and Babesia microti Among High-Risk Hispanic/Latino Workers on Eastern Long Island, New York: A Preliminary Cross-Sectional Analysis in 2016. Open For Infect Dis. (2019) 6:S596. doi: 10.1093/ofid/ofz360.1497

342. Vilcarromero S, Nunez AM, Vivas K, Russo J, Mahmood S, Wellins A$\mathrm{M}$, et al. 1645. High seroprevalence and seroconversion rate of Borrelia burgdorferi infection among Hispanic/Latino Immigrant Workers in Eastern Suffolk County, New York: A Longitudinal-Based Study. Open For Infect Dis. (2019) 6:S600. doi: 10.1093/ofid/ofz360.1509

343. Collins SM. Kay Hagan Tick Act. 1657. (2019). Available online at: https:// www.congress.gov/bill/116th-congress/senate-bill/1657/text/is (accessed July 22, 2021).

344. Brodin P. Immune determinants of COVID-19 disease presentation and severity. Nat Med. (2021) 27:28-33. doi: 10.1038/s41591-020-01202-8

Conflict of Interest: AGR is a scientific advisor to NeonMind Biosciences and ETHA Natural Botanicals. In conjunction with Dr. S. Sontakke and North Carolina State University, EBB holds US Patent No. 7,115,385; Media and Methods for Cultivation of Microorganisms, which was issued on October 3rd, 2006. He is a co-founder, shareholder and Chief Scientific Officer for Galaxy Diagnostics, a company that provides advanced diagnostic testing for the detection of Bartonella spp. and Borrelia infections. RM is a co-founder, shareholder and the Chief Technical Officer for Galaxy Diagnostics. RTM is a paid consultant/speaker for Zoetis and receives license related income from Zoetis. MJS serves on the Scientific Advisory Board for the Global Lyme Alliance and has been issued a patent [US Patent No. 10481 165] for "Elevated CCL19 after completion of therapy for acute Lyme disease identifies patients at risk for development of post-treatment Lyme disease syndrome who will benefit from further antibiotic therapy". AO has pending patent applications on the development of Lyme disease diagnostic tests.

The remaining authors declare that the research was conducted in the absence of any commercial or financial relationships that could be construed as a potential conflict of interest.

Publisher's Note: All claims expressed in this article are solely those of the authors and do not necessarily represent those of their affiliated organizations, or those of the publisher, the editors and the reviewers. Any product that may be evaluated in this article, or claim that may be made by its manufacturer, is not guaranteed or endorsed by the publisher.

Copyright (c) 2021 Bobe, Jutras, Horn, Embers, Bailey, Moritz, Zhang, Soloski, Ostfeld, Marconi, Aucott, Ma'ayan, Keesing, Lewis, Ben Mamoun, Rebman, McClune, Breitschwerdt, Reddy, Maggi, Yang, Nemser, Ozcan, Garner, Di Carlo, Ballard, Joung, Garcia-Romeu, Griffiths, Baumgarth and Fallon. This is an openaccess article distributed under the terms of the Creative Commons Attribution License (CC BY). The use, distribution or reproduction in other forums is permitted, provided the original author(s) and the copyright owner(s) are credited and that the original publication in this journal is cited, in accordance with accepted academic practice. No use, distribution or reproduction is permitted which does not comply with these terms. 